\title{
Los Menéndez Camina, Maestros de la Arquitectura Barroca Asturiana
}

\author{
Guillermo Bas ORdóÑeZ1 \\ The Menéndez Camina Family, Master Masons of the Barroque \\ Architecture in Asturias

\begin{abstract}
RESUMEN
Tradicionalmente dependiente de

ABSTRACT

Traditionally dependant of foreign masters

maestros foráneos y modelos clasicistas,

la arquitectura barroca asturiana

experimentó una importante renovación

de la mano de la dinastía de los

Menéndez Camina. Durante las últimas décadas del siglo XVII y XVIII, esta familia avilesina dominó los principales encargos arquitectónicos y aportó soluciones

novedosas al panorama edilicio de la

región.

PALABRAS CLAVE:

Asturias, arquitectura barroca, catedral de

Oviedo, Avilés and classical models, the barroque architecture in Asturias experienced an important renovation leaded by the Menéndez Camina dynasty. During the last decades of the $17^{\text {th }}$ and early $18^{\text {th }}$ centuries, this Avilés-born family dominated the main architectural commissions and contributed with important novelties to the region's building panorama.

KEYWORDS:

Asturias, baroque architecture, Oviedo cathedral, Avilés
\end{abstract}

\section{INTRODUCCIÓN}

El siglo XVII en Asturias es testigo de una amplia actividad constructiva que se manifiesta sobre todo en la arquitectura civil. En tanto que región periférica, los distintos estilos artísticos llegan al Principado con un cierto retraso respecto a otras partes del país, especialmente procedentes de Castilla, donde se localizan las principales fuentes de inspiración para el barroco asturiano. En este sentido, Asturias no actúa como generador de corrientes estilísticas sino que adapta diversas influencias foráneas. Son pocos los arquitectos nativos, pues la hegemonía continúa en manos de los canteros santanderinos, cuya llegada se registra ya a finales del siglo XV con la construcción de la catedral de Oviedo. No será hasta el siglo XVIII cuando abunden en términos relativos los arquitectos oriundos de la región.

\footnotetext{
1 Becario FPU, UNED, Departamento de Historia del Arte. Email: guillermobas@ bec.uned.es
} 
Por ello presenta especial interés la obra de la dinastía Menéndez Camina, formada por padre e hijo, ambos de nombre Francisco y oriundos de Avilés, y algunos parientes más. Sus proyectos se centran en el último cuarto del siglo XVII, extendiéndose a los primeros años de la centuria siguiente y su estilo consagra un estilo netamente decorativo a Asturias como reacción al clasicismo que había dominado las décadas anteriores. Como buenos exponentes de esa tendencia, los Menéndez Camina proyectaron edificios de diversa índole en las principales ciudades asturianas.

A lo largo de este artículo se analizará su obra, enmarcada en el panorama arquitectónico del Principado del momento. También es preciso realizar una reseña biográfica, con los datos que se conocen de sus vidas, y un resumen de la bibliografía publicada y los problemas que plantea. Finalmente, se analizarán las principales obras, documentadas o atribuidas con seguridad, de estos maestros, que incluyen edificios muy emblemáticos del barroco asturiano como el palacio de Revillagigedo y otros que, aunque menos conocidos, contribuyen al correcto conocimiento de su actividad.

\section{PANORAMA ARQUITECTÓNICO DE ASTURIAS EN EL SIGLO XVII}

Es necesario hacer varias consideraciones previas a la hora de analizar la arquitectura del siglo XVII en Asturias. En primer lugar, en cuanto a los límites cronológicos, es un siglo largo pues su comienzo antecede al año 1600. Durante el siglo XVI, se trabajaba a buen ritmo en la construcción de la catedral de Oviedo, cuyas obras de estilo gótico habían comenzado a finales del XIV. El cuerpo de naves había sido cerrado en 1498 pero las obras del pórtico y la torre se prolongarán durante décadas bajo la dirección de sucesivos maestros para convertirse en la principal creación arquitectónica del Principado durante ese siglo. Sólo en el remate de la torre, proyectado por Rodrigo Gil de Hontañón, aporta ya formas renacentistas.

Estas circunstancias, unidas al carácter periférico de Asturias, hacen que el renacimiento tenga escasa incidencia en el Principado y provocan una temprana llegada del clasicismo castellano, antecedente de las tendencias del siglo XVII. Si durante la primera mitad de la centuria la catedral había sido la principal obra, a finales del siglo XVI toma el relevo la Universidad, fundada en 1568 por Fernando de Valdés Salas y cuyo proyecto es encargado a Gil de Hontañón, a cuya muerte se hace cargo de las obras Juan del Ribero Rada (c. 1540-1600), uno de los principales exponentes del foco vallisoletano. Esta construcción constituye el punto de partida de la eclosión de la arquitectura civil que vive Asturias a lo largo del siglo XVII y que encuentra su máxima expresión en los diferentes palacios y casonas. 


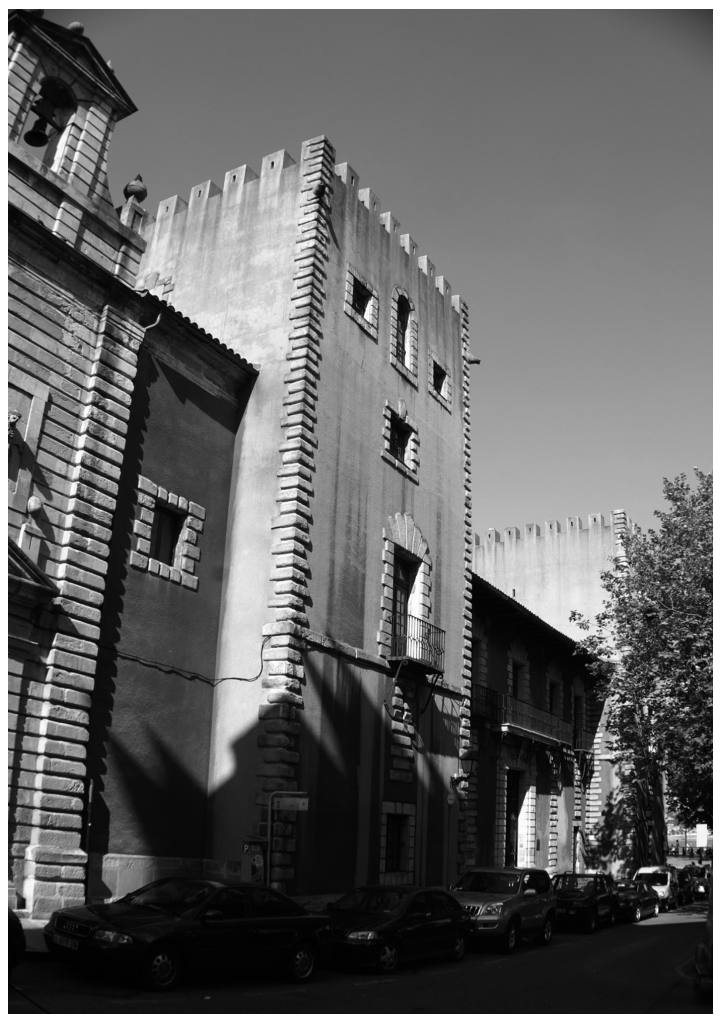

Palacio de Valdés en Gijón (principios del siglo XVII) modelo del palacio de Camposagrado y prototipo del esquema de palacio con fachada torreada. Obsérvese la ubicación de la capilla, anexa a la fachada.

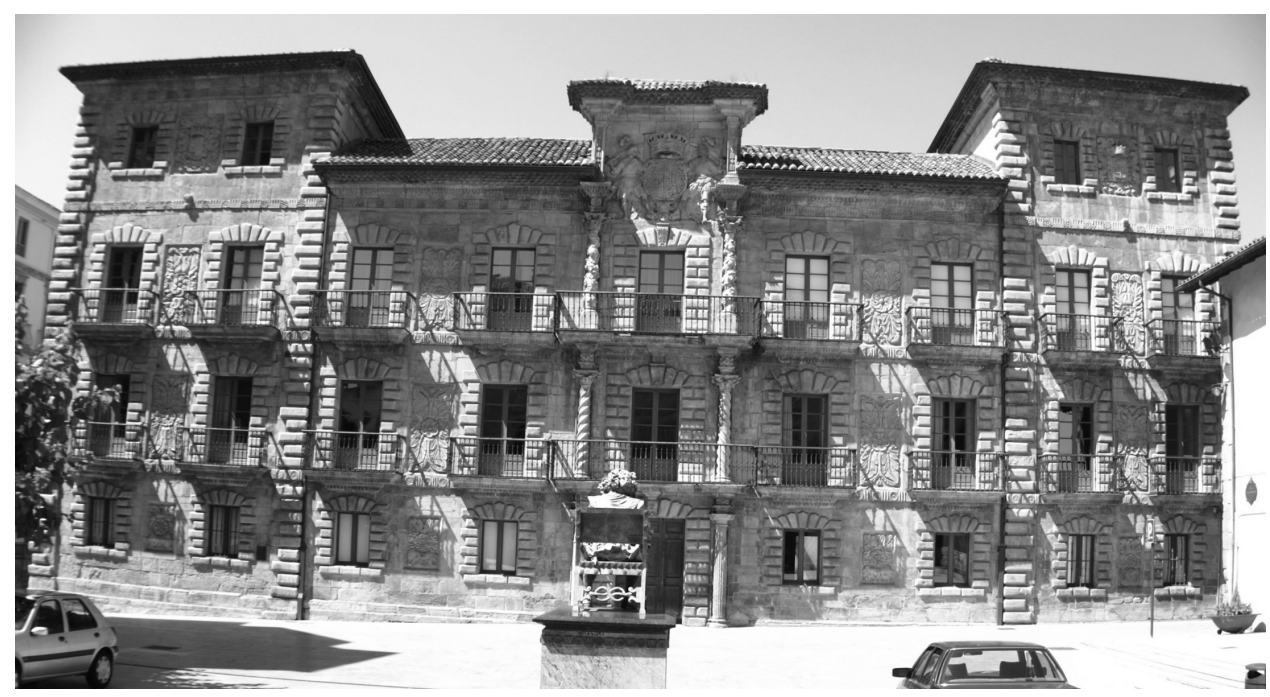

Fachada del palacio de Camposagrado en Avilés. El desarrollo de los paneles con florones provoca un interesante efecto plástico sobre la superficie del muro. 
La consagración del clasicismo vino de la mano del arquitecto cántabro Juan de Naveda (c. 1575-1640) que llega a Oviedo para realizar la girola de la catedral (1621) y termina proyectando el Ayuntamiento, una de las máximas muestras de ese estilo con elementos escurialenses en la región ${ }^{2}$. Si bien esta última opción no tuvo demasiada continuidad aquí, sí proporciona una de las pautas que guiarán el barroco asturiano: la tendencia clasicista, a la que contribuyen sobre todo dos factores: que el Principado se encuentra dentro de la órbita del barroco castellano, siempre más austero que el andaluz, y el aislamiento geográfico, que retrasa la llegada de nuevas corrientes y siempre tiende al conservadurismo estilístico.

Durante la primera mitad del siglo XVII se codifican en Asturias los modelos más genuinos del barroco, como el palacio con patio central, que pasa de ser un edificio entre medianeras a ser una construcción exenta. Además, poco a poco va ganando terreno la decoración, que comienza resaltando la portada de ingreso a los edificios civiles para extenderse, ya pasado el ecuador de la centuria, al resto del muro.

Es interesante en este punto dar unas pinceladas sobre la arquitectura palaciega, que tanta importancia adquiere en la época que nos ocupa. En primer lugar, existe una abismal diferencia decorativa y constructiva entre la fachada y el interior. Es la primera la que recibe una mayor atención, realizada frecuentemente en sillería y donde se concentra todo el ornato, reflejo de la pujanza económica de los comitentes. Sin embargo, los palacios barrocos asturianos son sorprendentemente espartanos en su interior, con gruesos muros de mampostería enlucida y abundante uso de la madera en las cubiertas e incluso en el cierre de los pisos superiores. Sólo dos zonas pueden recibir una mayor atención: el patio (que habitualmente se soluciona con columnas toscanas sustentando un entablamento sencillo) y la escalera, también de piedra pero sin demasiada carga decorativa ${ }^{3}$. Esta tendencia a la sobriedad y a un cierto clasicismo contagia incluso a algunos arquitectos foráneos de paso por Asturias. Es el caso de la estancia de Melchor de Velasco (1654-1658): sus obras en el Principado son mucho más comedidas de lo que será su etapa gallega, una vez conocido el barroco del foco santiagués.

La segunda reflexión atañe a la estructura de este tipo de edificios. Sin querer realizar una clasificación tipológica exhaustiva ${ }^{4}$, lo más habitual es encontrarnos con edificios de planta rectangular o cuadrada articulada en torno a un patio. Esta disposición puede sufrir alteraciones dependiendo de la existencia anterior o no de una torre medieval. En lo que respecta a la fachada, suele presentar más variantes; en los palacios urbanos puede presentarse como un cuerpo único (palacio de

\footnotetext{
${ }^{2}$ La obra de las casas consistoriales tendrá una notable influencia a lo largo de todo el siglo, especialmente en el proyecto del Ayuntamiento de Avilés, cuyas trazas fueron dadas por Juan de Estrada.

${ }_{3}$ En ocasiones el patio llega a adquirir una mayor monumentalidad, con arcos y cubierta abovedada en las crujías, como sucede en el palacio del duque del Parque o el de Camposagrado de Oviedo, ambos ejemplos ya del siglo XVIII.

${ }^{4}$ Cf. RAMALLO ASENSIO, Germán: La arquitectura civil asturiana (Época moderna). Salinas, Ayalga. 1978, pp. 23-50.
} 
Malleza, situado entre medianeras) aunque es muy frecuente encontrar una zona central flanqueada por sendas torres.

Por lo que respecta a la arquitectura religiosa, también experimenta una gran renovación en la centuria que nos ocupa, cuando grandes monasterios reedifican sus dependencias (Obona, La Vega, Cornellana) y se fundan o reconstruyen numerosos templos parroquiales. La variedad tipológica es más amplia, con templos de una o tres naves, cabeceras rectas, semicirculares o poligonales y la llegada de nuevos modelos como la iglesia jesuítica o la de cajón. Estas innovaciones coexisten con tradiciones procedentes del gótico, como las agujas o las bóvedas de crucería, que persisten especialmente en construcciones rurales.

En realidad, la arquitectura asturiana del siglo XVII es en buena medida «de autor» pues sus principales obras fueron trazadas por un amplio conjunto de maestros que individualizaron sus creaciones. Por ello no puede hablarse tanto de corrientes como de ciertas tendencias estilísticas que se solapan cronológicamente y a las que puede aproximarse más o menos cada edificio.

La llegada de una visión más decorativa encuentra una de sus primeras muestras en el palacio de Celles (Siero) encargado en $1668^{5}$. En él comienza la ruptura de los órdenes clásicos y se consagran elementos como las molduras orejeras, muy difundidas en Asturias, además de aplicarse una minuciosa geometría a la hora de trazar la planta.

5 En el contrato figura como tracista Diego de Gajano, maestro poco conocido que colaboró con Melchor de Velasco. Sin embargo, se ha atribuido el proyecto a Domingo de Andrade, que realizó en 1695 un retablo para Celles. v. MADRID ÁLVAREZ, Vidal de la: «Arquitectura barroca civil (II)» en BARÓN THAIDIGSMANN, Javier (dir.): El arte en Asturias a través de sus obras. Oviedo, Prensa Asturiana, 1996, p. 214. 


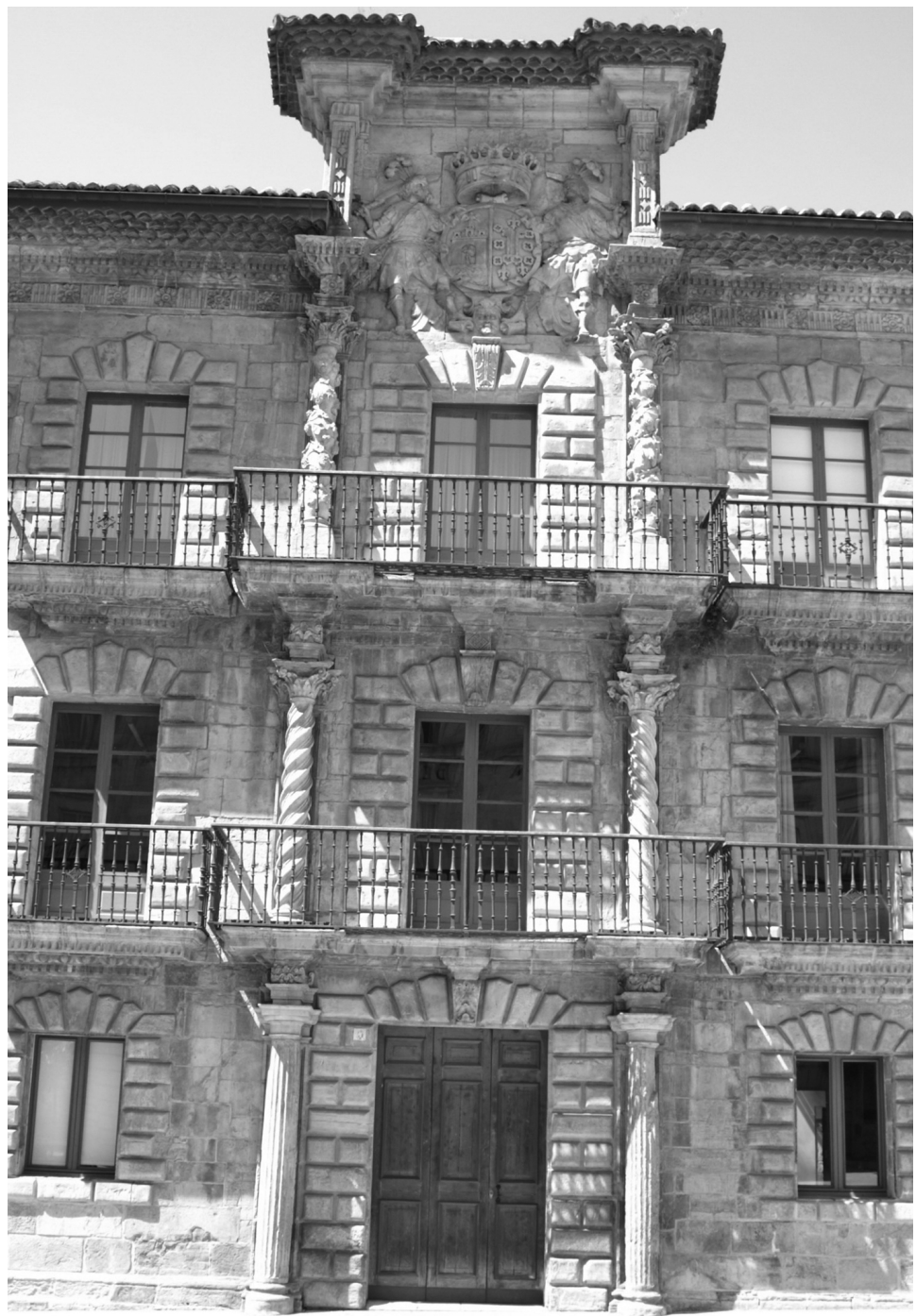

Calle central de la fachada del palacio de Camposagrado, construida a base de balcones muy desarrollados y superposición de órdenes, concediendo gran importancia al remate con escudo.

En este contexto aparece la obra de los Menéndez Camina, que lleva a sus extremos la carga decorativa. Este proceso se realiza de forma epidérmica, sin introducir innovaciones estructurales, lo que no resta en absoluto interés a su producción. El triunfo del barroco decorativo tiene lugar en Asturias entre 1690 y 1750, continuando la tendencia introducida por los Camina maestros foráneos, entre los que destacan el trasmerano Francisco de la Riva Ladrón de Guevara (1686-1741) y el asturiano Pedro Antonio Menéndez (1716-c. 1789). Pero no nos 
llevemos a engaño: el decorativismo se circunscribió a un limitado número de obras vinculado a la nobleza urbana más poderosa, coexistiendo con tendencias más conservadoras en los edificios rurales. En ningún momento llegó a ser un estilo dominante.

El final de esta corriente llegó con Manuel Reguera (1731-1798) primer asturiano que recibió el título de arquitecto por la Academia de San Fernando (1764) y fue discípulo de Ventura Rodríguez, que también proyectó obra para Asturias. Fueron ambos los responsables de la introducción del barroco clasicista dieciochesco que liquidará al decorativismo.

Como se ha comentado al principio de este apartado, el siglo XVII vive el florecimiento de la arquitectura palaciega asturiana. La nobleza de segundo orden es la clase dominante en el Principado, detentando el poder en los municipios y en la Junta General. Algunos de sus miembros ya eran caballeros de diferentes órdenes militares, pero es a lo largo de esta centuria cuando comienzan a recibir títulos. El primero es el de conde de Toreno, concedido a Álvaro Queipo de Llano en 1633, al que seguirán otros, si bien apenas eran un puñado antes de comienzos del XVIII. Curiosamente, Asturias era una de las zonas de España con mayor número de nobleza de segundo orden, pues los hidalgos llegaban a representar hasta un tercio de la población total ${ }^{6}$. La alta nobleza, procedente de un puñado de casas, acaparaba el gobierno en el medio centenar de señoríos en los que estaba dividido el Principado en la Edad Moderna y era la responsable de administrar justicia y percibir impuestos.

Durante el siglo XVII, coincidiendo con la adquisición de títulos, parte de esa nobleza erige su casa en las ciudades, especialmente en Oviedo y Gijón, como complemento de sus residencias solariegas. De esa manera, los palacios urbanos prosperan en los tiempos del barroco y se convierten en uno de los elementos de prestigio de esa clase emergente: su ubicación y su riqueza constructiva serán un fiel reflejo del poderío económico de sus dueños.

\section{LOS MENÉNDEZ CAMINA. RESEÑA BIO-BIBLIOGRÁFICA}

El arte asturiano de la Edad Moderna fue ignorado (o, en el mejor de los casos, tratado de manera sumaria) por los primeros estudiosos del renacimiento y del barroco español y su análisis no se ha producido hasta las últimas décadas, quedando todavía numerosos aspectos por sistematizar y diversas teorías por revisar; aún no se ha realizado ningún trabajo sobre la arquitectura asturiana del XVII como un conjunto. Dentro de esta situación, la arquitectura civil y la religiosa vinculada a la catedral de Oviedo han sido objeto de una mayor atención en tiempos recientes. Para el caso de los Menéndez Camina, el primer autor en acercarse a su

6 VV. AA.: Historia de Asturias. La Edad Moderna I. Gijón, Ayalga. 1977, p. 76. 
obra fue Germán Ramallo Asensio, dentro de las comunicaciones presentadas en el II Simposio sobre el Padre Feijoo y su tiempo (1976, aunque no publicadas hasta 1983), un artículo dedicado a los palacios de la los marqueses de Camposagrado en el que se atribuía a Francisco Menéndez Camina (padre) el de Avilés ${ }^{7}$. Las tesis planteadas aquí serían recogidas más tarde por este mismo autor, primero en 1978 un artículo pionero en torno al estilo de estos arquitectos. Este texto se centra en un bosquejo biográfico y en la obra de la capilla de Santa Eulalia de la catedral de Oviedo, obviando la obra civil, aunque aporta un interesante apéndice documental.

Casi simultáneamente, el profesor Ramallo publicó La arquitectura civil asturiana (Época moderna) que se centra en los palacios y casonas levantados en el Principado entre los siglos XVI y XVIII. En esta obra se comentan las obras más importantes de los Menéndez Camina en el ámbito de la edificación residencial, especialmente el palacio de Revillagigedo y el de Camposagrado, cuya autoría comienza a atribuirse a los arquitectos que nos ocupan. Este autor ha analizado alguna obra de los Camina de forma tangencial en otros artículos, como el dedicado a las capillas palaciegas en el VII Congreso del Comité Español de Historia del Arte (CEHA, celebrado en Murcia en 1988) en el que se cita la colegiata de San Juan Bautista de Gijón y se comentan las razones que llevaron a la construcción de un templo tan sobredimensionado ${ }^{8}$.

Más recientemente, las principales obras han sido analizadas por Ramallo y Vidal de la Madrid en El arte en Asturias. De este último es una monografía publicada con motivo de la apertura como sala de exposiciones del palacio de Revillagigedo: Palacio de Revillagigedo y colegiata de San Juan Bautista, aparecida en 1992 pero más destinada a un público no especializado.

Por otro lado, algunos aspectos de la obra de los Menéndez Camina, como su impacto en el tejido urbano de Avilés, han sido analizados en la obra colectiva El patrimonio artístico de Avilés, publicación que ofrece, dentro de su guía de monumentos, breves referencias a algunos edificios de estos arquitectos en la villa ${ }^{9}$.

7 RAMALLO ASENSIO, Germán: «Las casas urbanas de la familia Camposagrado» en VV.AA.: /I Simposio sobre el Padre Feijoo y su siglo (1976), pp. 575-592. Oviedo, Centro de Estudios del siglo XVIII. 1983.

8 RAMALLO ASENSIO, Germán: «El particular caso de las capillas palaciegas en la arquitectura barroca asturiana» en VV. AA.: Actas del VII Congreso Español de Historia del Arte. Murcia, Universidad de Murcia. 1992.

9 MADRID ÁLVAREZ, Vidal de la (coord.): El patrimonio artístico de Avilés. Avilés, Casa Municipal de Cultura. 1989. 


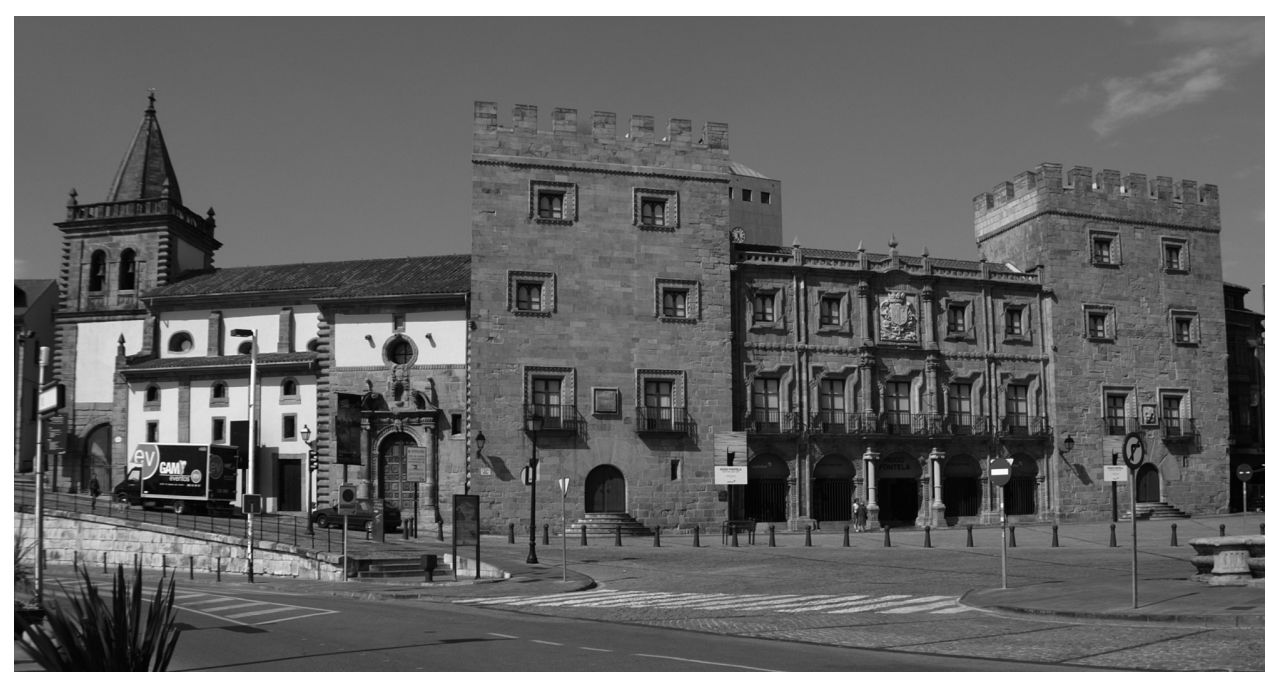

Vista general del palacio de Revillagigedo y la colegiata de San Juan Bautista de Gijón. La torre de la derecha es la original gótica, a la que Menéndez Camina añadió el cuerpo central y la nueva torre. La colegiata, una capilla palaciega muy desarrollada, se adapta a la ladera de Cimadevilla.

También Yayoi Kawamura ha analizado su primera intervención en la plaza mayor ovetense en una publicación monográfica ${ }^{10}$.

Durante los últimos tiempos han aparecido dos textos relevantes: el primero es un artículo sobre la capilla de Santa Eulalia, publicado por Vidal de la Madrid en la revista Liño. El segundo es la reciente monografía de Miguel Solís Santos sobre el barrio avilesino de Sabugo, que incluye información biográfica relevante sobre esta familia.

Esta aparente abundancia de trabajos esconde sin embargo numerosas carencias. En primer lugar, la obra de los Camina no se ha tratado nunca de forma sistemática y ni tan siquiera se han ordenado todas las referencias biográficas que se tienen de esta familia. Tampoco se ha realizado un estudio de la trascendencia posterior de su obra.

Por desgracia, son muy pocos los datos que se conocen de la dinastía Menéndez Camina y prácticamente todos ellos se circunscriben al ámbito profesional. El primero de sus miembros fue un tal Martín de Camina, un herrero vecino del barrio avilesino de Sabugo, del que se sabe que transportó carretadas de piedra para adoquinar varias calles de la villa ${ }^{11}$. Es plausible que fuera el padre de otro Martín,

10 KAWAMURA, Yayoi: Arquitectura y poderes civiles en Oviedo 1600-1680. Oviedo, RIDEA. 2006.

11 RAMALLO ASENSIO, Germán: «El decorativismo en la arquitectura barroca asturiana. Los Menéndez Camina» en VV.AA.: Actas de la I Semana del Patrimonio Artístico Asturiano. Oviedo, Universidad de Oviedo. 1979, p. 83. 
que contrajo matrimonio en 1665 con una tal Úrsula de Torano ${ }^{12}$. El siguiente personaje de la saga es Juan Menéndez Camina, que colaboró en 1639 en obras realizadas en el castillo de San Juan de Nieva, bajo las órdenes del maestro cántabro Gonzalo de Güemes Bracamonte ${ }^{13}$.

Su hijo fue Francisco Menéndez Camina (padre), nacido probablemente hacia 1629, que es el primero en dedicarse por completo a la arquitectura. Su primera referencia data de 1663, cuando interviene en la capilla de los Alas de la iglesia de San Nicolás de Avilés (actual templo de los franciscanos). Se desconoce el alcance de su colaboración en este pequeño edificio rectangular cubierto con dos bóvedas de crucería y prácticamente sin decoración ${ }^{14}$. En 1672 firma un contrato para ejecutar una vivienda para un tal Francisco Rodríguez, sastre de profesión. No sabemos nada de su juventud, pero figura en como «maestro arquitecto, de cantería y, anssimismo, ensanblador» lo que ha llevado a Yayoi Kawamura a plantear la hipótesis de que se formase en la esfera de los retablos, lo que explicaría su gusto por el decorativismo en tiempos posteriores ${ }^{15}$. Por cierto que Camina es uno de los primeros asturianos que aparece con el título de arquitecto, quizá por herencia del mundo de la retablística. A pesar de carecer de formación académica, esta circunstancia ya preludia la nueva condición social que estos maestros irán progresivamente adquiriendo.

El 9 de marzo de 1674 aparece por vez primera en Oviedo con Pedro Suárez como tasador de la casa de la madre de Gregorio Bayón, colector de las bulas para la Santa Cruzada de 1673. El objeto de la operación era adquirir el inmueble para ampliar la plaza mayor a instancias del consistorio ovetense, que pretendía adquirir tres casas situadas frente al propio ayuntamiento. Otros arquitectos intervinieron en el proceso, como Pablo de Cubas, pero finalmente la ampliación no se llevó a cabo. Por esos mismos años, se documenta su intervención en la fachada de la iglesia de los jesuitas (actual San Isidoro) cuyo alcance se discutirá más abajo. En 1675, Camina se encarga de realizar la capilla mayor de la iglesia de Latores, cerca de Oviedo, con Juan González y Pedro Fernández Lorenzana ${ }^{16}$. Tres

12 SOLÍS SANTOS, Miguel: Sabugo. El barrio marinero de Avilés durante el Antiguo Régimen. Oviedo, Consejería de Cultura y Turismo/KRK Ediciones, 2010, pp. 359-361. Se sabe que el padre de ese Martín se llamaba igual que su hijo, por lo que es coherente que fuera la misma persona vinculada con el adoquinado. El apellido Camina podría tener sus orígenes en la aldea homónima de la parroquia de Cancienes, en el municipio de Corvera. El autor utiliza la forma antigua del apellido, Menéndez de Camina

13 MADRID ÁLVAREZ, Vidal de la (coord.): El patrimonio artístico de Avilés. Avilés, Casa Municipal de Cultura. 1989, p. 63. Según el autor, este personaje falleció en 1661, pero no aparece ninguna mención a él ni a su parentesco con el resto de la saga en la obra de Solís Santos.

14 Me refiero aquí a la segunda capilla de los Alas. No confundir con la primitiva capilla funeraria de esta familia, famosa obra gótica del siglo XIV también próxima al templo de San Nicolás.

15 KAWAMURA, Yayoi: Arquitectura y poderes civiles en Oviedo 1600-1680. Oviedo, RIDEA. 2006, p. 121 , nota 391.

${ }_{16}$ De Fernández Lorenzana se conserva algún dato de otras obras suyas, como una casa particular contratada en 1670 para Antonio de Valdés, en el barrio ovetense de San Lázaro. Ambos intervendrán años más tarde en la iglesia de Santa María de la Vega. Cf. KAWAYURA, Yayoi, op. cit., p. 176 y nota 653. 
años más tarde, interviene en la hospedería del monasterio de San Vicente en la capital del Principado ${ }^{17}$.

En 1685, Francisco está trabajando en la reforma del palacio del marqués de Camposagrado en Avilés, del que como veremos es autor de su fachada delantera. Ese mismo año está documentada su intervención, en colaboración con su hijo mayor, en obras realizadas de nuevo en San Juan de Nieva ${ }^{18}$. Tres años después es tasador, junto con Domingo Suárez Solar, de la reedificación de la capilla mayor de San Martín de Laspra (Castrillón) obra de Agustín Martínez de Celis. Y por fin, en 1690, contrata el proyecto para la capilla de Santa Eulalia en la Catedral, que le consagra como arquitecto y le permite adquirir una casa en Avilés. Su intervención en Oviedo le valió el título de maestro de obras del templo catedralicio y supervisó las obras realizadas en iglesias dependientes de él, como las de Tuñón, San Martín de Proaza, Agüeras y Casares. Falleció con seguridad antes de febrero de 1697, quizá en el año $1694^{19}$.

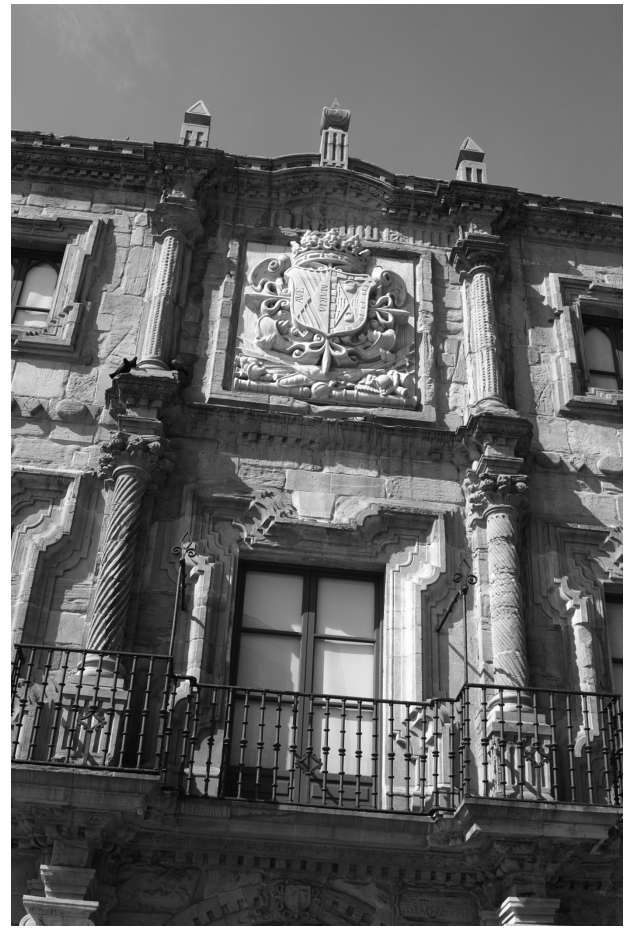

Remate de la fachada del palacio de Revillagigedo. El desarrollo de las orejas como motivo decorativo es palpable.

17 MADRID ÁLVAREZ, Vidal de la: «El obispo Fray Simón García Pedrejón y la capilla de Santa Eulalia de Mérida en la catedral de Oviedo (1690-1696). Nuevas aportaciones». Liño no 14, Oviedo, 2008, p. 47, nota 25. La lista incluye otras obras, como la bóveda de la capilla del Espíritu Santo en el convento de San Francisco de Avilés (1670)y el hospital y cárcel de la plaza mayor de esa villa (1675).

18 Ídem nota 6.

19 MADRID ÁLVAREZ, Vidal de la: op. cit., p. 47, nota 35. 
Su hijo mayor, también de nombre Francisco, contrajo matrimonio el 30 de diciembre de 1679 con María Rodríguez de Graíño en la parroquia avilesina de San Nicolás ${ }^{20}$. Respecto a su actividad profesional, en su villa natal ocupó el cargo de fontanero municipal entre 1689 y 1692, periodo durante el que realizó el pórtico y cabildo de la iglesia de San Nicolás, y colaboró con su progenitor en la capilla de Santa Eulalia. En 1697 interviene como tasador nombrado por la comunidad de Santa María de la Vega (Oviedo) en un pleito contra Fernández Lorenzana, maestro que había realizado el templo de dicho monasterio. No se tiene constancia de más intervenciones en esta construcción ${ }^{21}$.

En 1699, contrató con el marqués de Camposagrado el remate del convento y la iglesia de la Merced en Avilés. Fue él quien diseñó la ampliación del palacio de Revillagigedo y la colegiata de San Juan Bautista, en Gijón. En 1702, se documenta una intervención suya en los muelles del puerto de gijonés y parece que después pasó algún tiempo en Galicia. Con posterioridad, trabajó efectuando arreglos en la desaparecida casa de los Alas, frente a la iglesia de San Nicolás ${ }^{22}$. Parece que falleció en $1719^{23}$.

El hijo pequeño, Valentín Menéndez Camina, también tomó parte en la obra de la Santa Eulalia y, en 1695, con su hermano es fiador de los encargados de mantener las fuentes públicas en Oviedo ${ }^{24}$. No es arriesgado pensar, aunque no existe constancia de ello, que colaborase en las obras de Revillagigedo.

Finalmente, Bernardo Menéndez Camina, hijo probablemente de uno de los dos hermanos ${ }^{25}$, trabajó en 1738 en otra reparación del puerto de Gijón en compañía de otros arquitectos como Juan Suárez Muñiz, José González Iglesias y el más conocido Francisco de la Riva Ladrón de Guevara.

20 SOLÍS SANTOS, Miguel: op. cit., p. 360.

21 MARTÍNEZ VEGA, Andrés: «Las manifestaciones artístico-culturales de la comunidad benedictina de la Vega». BIDEA no 135, Oviedo, 1990, pp. 483-484. El templo de Santa María de la Vega había sido realizado por Fernández Lorenzana y Juan González siguiendo las trazas de Gregorio de la Roza. Fue derribado en 1917.

22 SOLÍS SANTOS, Miguel: op. cit., pp. 362-363.

23 MADRID ÁLVAREZ, Vidal de la: op. cit., p. 47, nota 25. No parece haber acuerdo acerca de este punto, pues Solís Santos (op. cit., p. 367) afirma que un tal Francisco Menéndez Camina, fallecido el 27 de septiembre de 1719 no es el mismo que el arquitecto, ya que se había casado en junio de 1718 con Francisca del Río. No es del todo imposible que ambos sean uno y el mismo, pero hemos de aceptar entonces la muerte de su primera mujer, María Rodríguez de Graíño (que aún vivía en enero de 1717) y un matrimonio en segundas nupcias relativamente rápido. Tampoco sería descabellado pensar que el Francisco fallecido en 1719 fuese hijo del que nos ocupa.

${ }^{24}$ Los maestros fontaneros de la ciudad son Pedro Morán y Leonardo Nicolás, que firmaron la escritura para el mantenimiento de las fuentes el 14 de abril de 1695. Ambos habían ocupado ya ese cargo (Morán en 1673-1687 e Izquierdo de 1687 en adelante) y el contrato tenía una duración de ocho años, que no llegaron a cumplir tal vez por fallecimiento. En enero de 1697 fueron sustituidos por Jerónimo Álvarez. Cf. KAWAMURA, Yayoi: op. cit., pp. 65-67 y nota 204.

${ }^{25}$ Existe una cierta confusión acerca de la relación entre los Menéndez Camina en el barrio de Sabugo y la familia de arquitectos. En mi opinión, Bernardo puede ser el mismo que actuó en como padrino en la boda de su hijo Joseph el 30 de junio de 1737. Cf. SOLíS SANTOS, Miguel, op. cit., p. 361. 
¿Podemos hablar de un «estilo Menéndez Camina»? A mi juicio no, pero ciertamente existen algunos recursos peculiares que pasaron del padre al hijo y que permiten distinguir la obra de la familia de la de otros maestros coetáneos sin llegar a constituir una verdadera corriente estilística. En primer lugar, el uso abusivo de los dentículos como elemento decorativo, no sólo en el lugar que les asignan las normas clásicas. También la tendencia a proyectar fachadas claramente reticuladas utilizando elementos arquitectónicos para dividir el muro y recurriendo con frecuencia al uso de balcones de forja. Otro motivo identificativo es la aparición de portadas con estructura de arco de triunfo coronadas por un frontón partido formado por volutas ${ }^{26}$. Finalmente, los Camina no pudieron escapar de la órbita clasicista en otros aspectos, como las fachadas rigurosamente planas, sin movimiento del muro (práctica desconocida en Asturias) o el uso de los órdenes a menudo de una forma bastante convencional.

\section{PRINCIPALES OBRAS}

\section{Palacio de Camposagrado}

La intervención de Francisco Menéndez Camina (padre) en el palacio de Camposagrado es una de sus primeras obras de importancia, consagrándole como arquitecto al servicio de la nobleza local y abriéndole las puertas de su gran obra en Oviedo. El primitivo palacio de los marqueses de Camposagrado ${ }^{27}$ en Avilés fue levantado a finales del siglo XVI, anexo a la muralla y con una fachada trasera que daba a la dársena que separaba el casco urbano avilesino del arrabal de Sabugo ${ }^{28}$, siguiendo el contorno de la cerca medieval de la villa. Es una construcción bastante convencional dentro de la arquitectura palaciega del momento en la región, con planta rectangular en torno a un patio central con muros cerrados, concebido únicamente como zona de servicios ${ }^{29}$.

Se desconoce si la construcción original ya presentaba las cuatro crujías (lo que parece más plausible) o si por el contrario adoptaba una planta en U. La fachada tra-

${ }^{26}$ El empleo de dentículos en la decoración (con un sentido más clasicista, obviamente) había sido introducido por Juan de Naveda en Asturias. En cuanto a las portadas monumentales, se ensayaron ya en el edificio de la universidad ovetense, pero su primera muestra en el Principado fue proyectada por Juan del Ribero para la iglesia de San Vicente de Oviedo (actual Santa María de la Corte).

${ }_{27}$ Este título había sido otorgado en 1661 a la familia Quirós, linaje de gran arraigo en la Asturias central desde la Baja Edad Media. Durante el siglo XVIII, los Camposagrado edificarán más palacios en Oviedo (actual sede de la Audiencia en la Plaza de Porlier) y Mieres (hoy instituto de secundaria Bernaldo de Quirós), en este último caso incluyendo la primitiva torre circular medieval.

28 El entorno urbano de este edificio se ha visto radicalmente transformado durante los últimos dos siglos. En el siglo XIX la muralla fue derribada y la dársena desecada, levantándose en su solar el actual Parque del Muelle.

29 RAMALLO ASENSIO, Germán: «Las casas urbanas de la familia Camposagrado» en VV.AA.: // Simposio sobre el Padre Feijoo y su siglo (1976). Oviedo, Centro de Estudios del siglo XVIII. 1983, p. 580 . 
sera, originalmente un mirador sobre la ría, presenta el interés de abrirse mediante una galería de arcos escarzanos en su segundo piso, de elegante diseño.

En 1686 ya está documentada la intervención de Menéndez Camina en el inmueble, según parece realizando reformas interiores que afectaron a su escalera, puertas, etc. Diez años después se contrata la realización de la fachada con los maestros de cantería Agustín Martínez, Domingo de Festas e Isidoro Martínez. Prácticamente no hay noticias sobre estos personajes, pero las trazas de la obra han sido atribuidas a Camina ${ }^{30}$, algo muy verosímil a juzgar por la composición de la fachada y sus motivos decorativos y apoyada por su vinculación anterior con este mismo palacio.

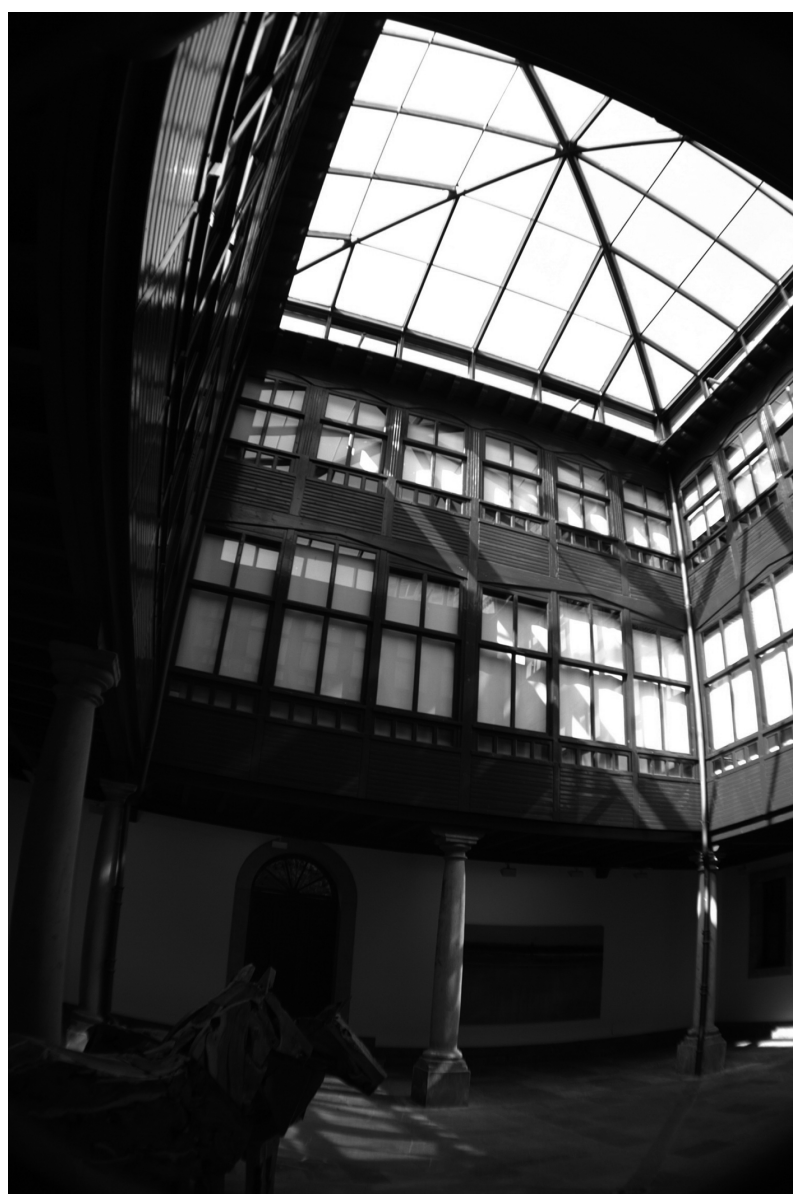

Patio central del palacio de Revillagigedo. Aunque muy restaurado, refleja el sencillo interior de los palacios barrocos asturianos, con galerías de madera sostenidas por columnas toscanas.

30 Inicialmente la obra había sido atribuida por Luis Bellido a Francisco de la Riva Ladrón de Guevara, hipótesis no muy realista teniendo en cuenta que este arquitecto había nacido en 1686. 
En su escritura de obra se especifica que se tome como modelo la casa de Pedro Valdés en Gijón, es decir, que la fachada ha de componerse como un cuerpo central de tres alturas y dos torres laterales de cuatro. Los vanos se disponen de forma ordenada, en forma de ventanas en el bajo y pisos altos de las torres y como balcones con barandillas de forja en los pisos $1^{\circ}$ y $2^{\circ}$. El principal motivo decorativo es el almohadillado, que se usa para recercar los vanos, en las esquinas y para diferenciar los volúmenes constructivos. En los paños de muro encontramos paneles con florones ligeramente rehundidos, de igual altura que los vanos y que proporcionan sutiles combinaciones de luces y sombras. Camina realiza aquí un interesante juego de organización del muro, pues, a diferencia de otras obras posteriores, no se utiliza el elemento arquitectónico para organizar el paramento sino simplemente la disposición de los vanos y los relieves hasta crear una retícula perfectamente marcada.

Es la calle central la que concentra la mayor carga decorativa, pues queda resaltada por sucesivos órdenes de columnas. En el piso bajo son de orden toscano flanqueando el portalón de ingreso, mientras que en el primero son compuestas con fustes de estriado espiral, contando con un balcón corrido entre los tres vanos centrales. Por último, en el piso alto adquieren la forma de columnas salomónicas con fustes decorados con guirnaldas y sosteniendo un arquitrabe con friso de glifos y remate de dentículos. Toda la coronación de la fachada se realiza mediante un alero bastante volado del que arranca la cubierta de teja, desechando el resquicio de fortaleza de las torres almenadas del palacio de Valdés. Sin embargo, toma de la construcción gijonesa el empleo abusivo del almohadillado en vanos y esquinas, cuya inspiración se encuentra en el tratado de Serlio.

Pero el elemento más espectacular de la fachada lo encontramos en su remate. En la calle central, una gran peineta aloja el escudo de los Quirós, escoltado por dos soldados. Este cuerpo está protegido por un tejaroz sostenido por dos pilastras cajeadas con diamantes y cuadrados estriados a modo de triglifos, continuando los órdenes de columnas de los pisos bajos y rompiendo la cornisa. La altura de este cuerpo decorativo casi alcanza la de las torres laterales y es la mejor muestra del afán de ostentación de los linajes asturianos de la Edad Moderna. Si bien los escudos en las fachadas eran habituales en ese momento, su monumentalidad nunca había alcanzado cotas tan altas, apareciendo generalmente integrados en la fachada. Algunos años antes se había dado algún intento de resaltar el escudo alzando la cornisa, como en el palacio de Celles (Siero) pero nunca de forma totalmente exenta. Tal es el atrevimiento de esta solución que prácticamente no se volvió a repetir, ni siquiera en obras posteriores de los Menéndez Camina como el palacio de Revillagigedo, donde el elemento heráldico vuelve a integrarse en el muro. Sólo hay otros dos casos comparables: la vicaría del monasterio de San Pelayo en Oviedo (proyectada por Fr. Pedro Martínez de Cardeña en 1703) y el más tardío hospicio provincial, actual Hotel Reconquista (trazas de Pedro Antonio Menéndez, 1752). 
Finalmente, hay que destacar que, tanto en este palacio como (sobre todo) en el de Revillagigedo, la importancia decorativa de la fachada se reparte entre los diferentes pisos aunque sea uno de ellos el principal. Esta corriente contrasta con el modelo de los palacios ovetenses (Malleza, Camposagrado, etc) en el que se hace patente la supremacía del piano nobile. El bajo queda reducido a una entreplanta destinada a zona de servicios y abierta mediante saeteras o aspilleras. Esta solución arcaizante es superada a partir de los Camina por una fachada abierta, en la que todas sus alturas reciben abundante luz exterior aunque no sean áreas de prestigio. Esta tendencia se desarrollará durante el siglo XVIII, culminando en obras como el palacio de Velarde, de Manuel Reguera.

\section{Palacio de Revillagigedo y colegiata de San Juan Bautista}

La obra más conocida de la dinastía Menéndez Camina, y uno de los edificios más emblemáticos del barroco asturiano es el palacio de Revillagigedo y la anexa colegiata de San Juan Bautista, en Gijón. Su promotor fue Carlos Ramírez de Jove (investido con el título de marqués de San Esteban del Mar de Natahoyo en 1707) que era propietario de una torre gótica, levantada probablemente a finales del siglo $\mathrm{XV}$, junto al puerto de la villa gijonesa, extramuros de la cerca medieval pero muy próxima a una de sus puertas. En cierto momento, Jove decidió ampliar su residencia y levantar un palacio, cuya cronología se había situado inicialmente a partir de 1690. Actualmente se sabe que Francisco Menéndez Camina (hijo) se encontraba midiendo el solar del palacio en 1705, pues la futura construcción cortaba parte de la calle que pasaba a la Pescadería ${ }^{31}$.

Paralelamente, se proyectó una gran capilla anexa al palacio y financiada por el prior de la catedral de Oviedo, Luis Ramírez de Jove, tío del marqués. Las obras de la construcción del templo, actual colegiata de San Juan Bautista, se remataron en 1723 bajo la supervisión de Pedro Muñiz Somonte siguiendo la traza original de Menéndez Camina.

Centrémonos ahora en el análisis del palacio. Su planteamiento es en principio convencional, con un cuerpo central flanqueado por torres siguiendo los ejemplos que hemos visto de Valdés y Camposagrado. Sin embargo, aquí encontramos una circunstancia muy singular: el arquitecto, a comienzos del siglo XVIII, copia exactamente la torre gótica (situada en el extremo sur) levantando una gemela al norte de la zona de nueva planta, ésta última de factura totalmente barroca. Así, las dos torres presentan un aspecto macizo, con muros de grandes sillares y pequeños vanos rectangulares decorados con alfiz ornamentado con bolas. El acceso se

31 La datación inicial proviene de Julio Somoza y García Sala. El documento de 1705 fue publicado por primera vez en RAMALLO ASENSIO, Germán: La arquitectura civil asturiana (Época moderna). Salinas, Ayalga. 1978, pp. 148-154. Cf. MADRID ÁLVAREZ, Vidal de la: Palacio de Revillagigedo y Colegiata de San Juan Bautista. Oviedo, Caja de Ahorros de Asturias. 1992, p. 13 y nota 1. 
efectúa mediante puertas de arco de medio punto con grandes dovelas y el remate es, en ambos casos, almenado ${ }^{32}$. Cada torre muestra el escudo de la familia en el primer piso.

Mayor complejidad encontramos en el cuerpo central. Su articulación está emparentada con la casa de García Pumarino en Avilés (v. infra) y en ella priman, aunque de un modo menos visible, los elementos arquitectónicos. Consta de tres pisos divididos en cinco calles. El bajo se abre como una galería porticada, justificada por la presencia de intercambios comerciales hasta 1791, mientras que en el piso noble encontramos balcones y en el superior, ventanas rectangulares. Esta disposición de huecos se corresponde aproximadamente con los pisos de la torre gótica. En la calle central, algo más amplia, la altura superior está ocupada por el escudo familiar.

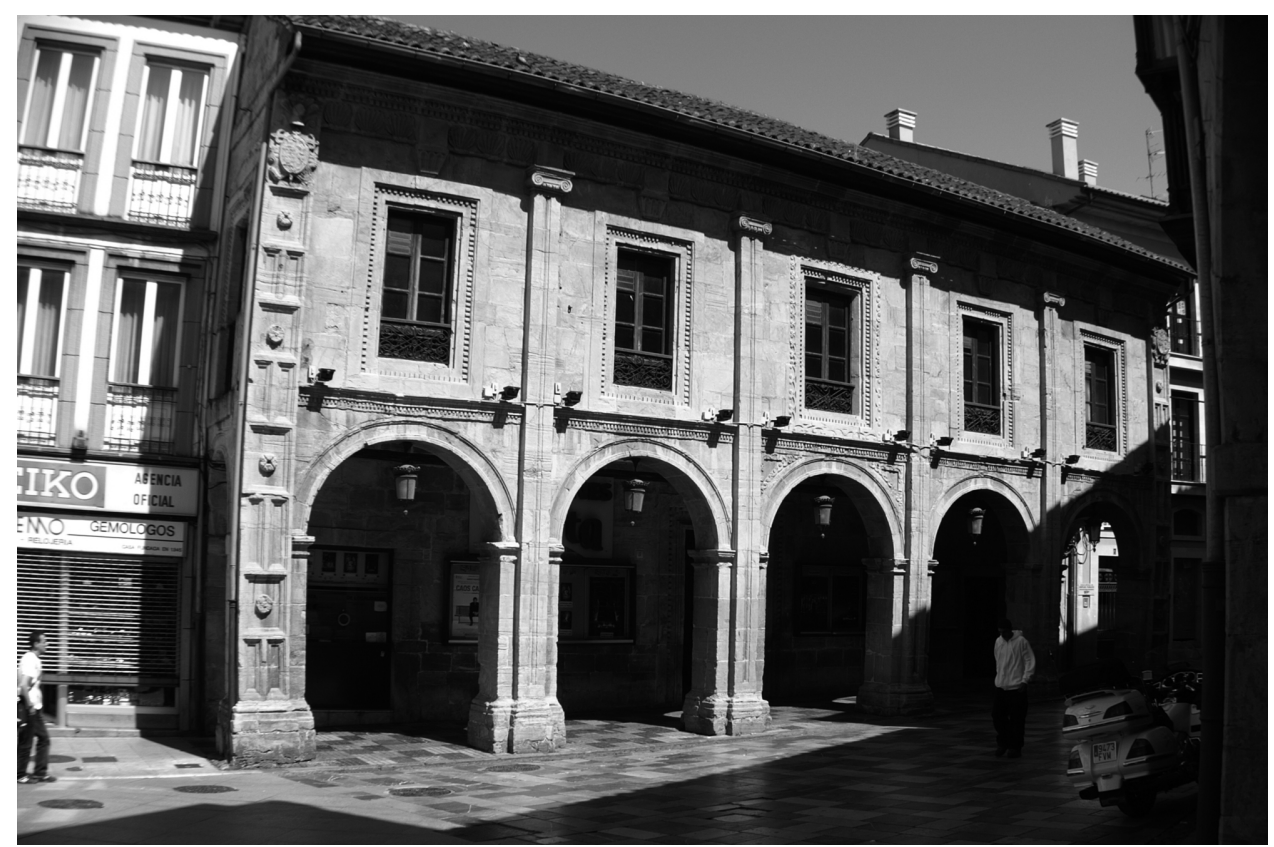

Casa de los García Pumarino en Avilés. Modelo de vivienda urbana señorial adaptada a los parámetros de la arquitectura local con la inclusión de soportales. Mediante el uso de recursos clásicos, Menéndez Camina incluye discretas referencias al propietario mediante la inclusión de escudos y friso de veneras en alusión a la orden de Santiago, de la que era caballero el comitente.

La división de calles se realiza mediante pilastras cajeadas ornamentadas con florones. Para los pisos, se emplean los propios balcones, muy moldurados, y un friso de óvalos y diamantes entre el segundo y el tercero. Los vanos se recercan

32 La única reforma que recibió la torre original fue la ampliación de los vanos del primer piso, convirtiéndolos en balcones. 
con molduras y orejas muy desarrolladas excepto las arquerías inferiores, que se decoran con pequeños dentículos. La calle central, en tanto que zona principal de la fachada, se anima con órdenes superpuestos de columnas: de orden jónico y fuste estriado en el bajo, corintias con estrías en espiral en el piso noble y semicolumnas en el superior. Toda esta disposición de órdenes es deudora de la empleada en el palacio de Camposagrado, pero con un remate de fachada mucho más discreto, a base de una pequeña balaustrada ligeramente resaltada en la zona central.

En realidad, la organización de la fachada se inspira en el proyecto realizado por Fray Pedro Martínez de Cardeña en 1703 para la vicaría del monasterio de San Pelayo en Oviedo. Allí se aplica ya la estructura de bajo porticado, primer piso con balcones y segundo con ventanas, así como la división utilizando columnas exentas y balcones. Sin embargo, es curioso que, al igual que en San Pelayo y como se había hecho en Avilés, no se haya recurrido a la peineta para el remate.

Como sucede en la arquitectura señorial asturiana de esta época, el interior del palacio apenas presenta decoración. Se articula en torno a un patio, descentrado respecto a la fachada, y que presenta dos pisos. El inferior está formado por columnas toscanas que soportan la galería de madera del piso superior, en la actualidad formada por tablillas horizontales y abierta mediante varias ventanas. Esta disposición copia la aplicada casi un siglo antes en el vecino palacio de Valdés.

La colegiata de San Juan Bautista, por su parte, es un edificio sumamente complejo. Su situación, al sur del palacio, es copia de la capilla del palacio de los Valdés, pero aquí adquiere una forma irregular para adaptarse al terreno (se encuentra ya en la ladera del cerro de Cimadevilla). Así, su eje forma un ángulo con la fachada del palacio y el propio ábside se encuentra embutido en éste, ofreciendo en realidad dos fachadas: la de los pies y la sur. Su construcción se enmarca dentro del proceso de "gigantismo» que sufren las capillas palaciegas asturianas desde finales del siglo XVII, con casos como la de Santa Ana en Meres (Siero), la de los Dolores en Grado y la propia colegiata de Pravia, todas edificadas antes de $1730^{33}$. Añaden así a la función primigenia de oratorio privado otras dos: la de reflejar el prestigio de su promotor y la de servir como panteón familiar. Por último, es necesario tener en cuenta la ausencia de conventos importantes o grandes templos en los que las familias nobles pudiesen costearse los enterramientos, al contrario de lo que ocurría en Avilés u Oviedo, forzando capillas más monumentales.

Volviendo a la que nos ocupa, presenta planta basilical de tres naves, la central bastante más ancha que las laterales, con un crucero muy desarrollado y ábside único irregular. Las naves se separan mediante arcos soportados por gruesos pilares de orden jónico cajeados como si contuvieran en su interior una columna. So-

${ }^{33}$ Existían algunos ejemplos anteriores que apuntaban esta tendencia hipertrófica, como la capilla del palacio de los Omaña en Tineo y la de Llamas de Mouro. 
bre las naves laterales se sitúan pequeñas tribunas que se abren mediante arcos rebajados y se corresponden con una situada a los pies, en el primer tramo de la nave central. Todo el cuerpo de naves se cubre con bóvedas de cañón reforzadas con fajones y decoradas con yeserías. En la central se abren lunetos que alojan los arcos de las tribunas y pequeños óculos de iluminación. Por su parte, el crucero se cubre con bóvedas de crucería de inspiración gótica ${ }^{34}$, disposición que se repite en la bóveda nervada que cierra la cabecera. Esta estructura es una copia a escala y adaptada al solar de la iglesia de los jesuitas de Oviedo (actual parroquia de San Isidoro) a su vez una versión de la planta jesuítica planteada por Vignola a finales del siglo XVI.

A los pies del templo se dispone una torre de planta oblonga y proporciones bastante achaparradas, abierta en la parte baja con arcos de medio punto, siguiendo una disposición muy habitual en las parroquias rurales asturianas del momento. Se corona con una aguja maciza de planta poligonal ${ }^{35}$. La decoración se centra en los sillares almohadillados de las esquinas, las molduras que separan los pisos y la pequeña balaustrada que remata el cuerpo de la torre. Fue la última parte del templo en ser realizada.

El brazo sur del transepto actúa como fachada principal, por lo que recibe un tratamiento decorativo excepcional. Cuenta con una portada monumental, de arco de medio punto decorado con dentículos y flanqueado por columnas jónicas que sostienen un entablamento con almohadillado y cabezas de querubines. Por encima, sendas volutas flanquean una hornacina central. La disposición general de esta portada es un trasunto de las realizadas unos años antes para la capilla de Santa Eulalia, si bien aquí adquiere una mayor monumentalidad por encontrarse en el exterior. Un pequeño friso de dentículos separa esta zona de la parte alta, en la que se abre un óculo. Como en la torre, en las esquinas de esta fachada se disponen grandes sillares almohadillados.

${ }^{34}$ Este sistema había sido utilizado en la primera traza de Francisco Menéndez Camina (padre) para la capilla de Santa Eulalia de la catedral de Oviedo.

${ }^{35}$ Este tipo de estructuras, de inspiración gótica, habían sido puestas de moda en Asturias por la obra de Melchor de Velasco para la iglesia de San Pelayo de Oviedo (1656) obra ésta concebida expresamente como un trasunto de la aguja de la vecina catedral. 


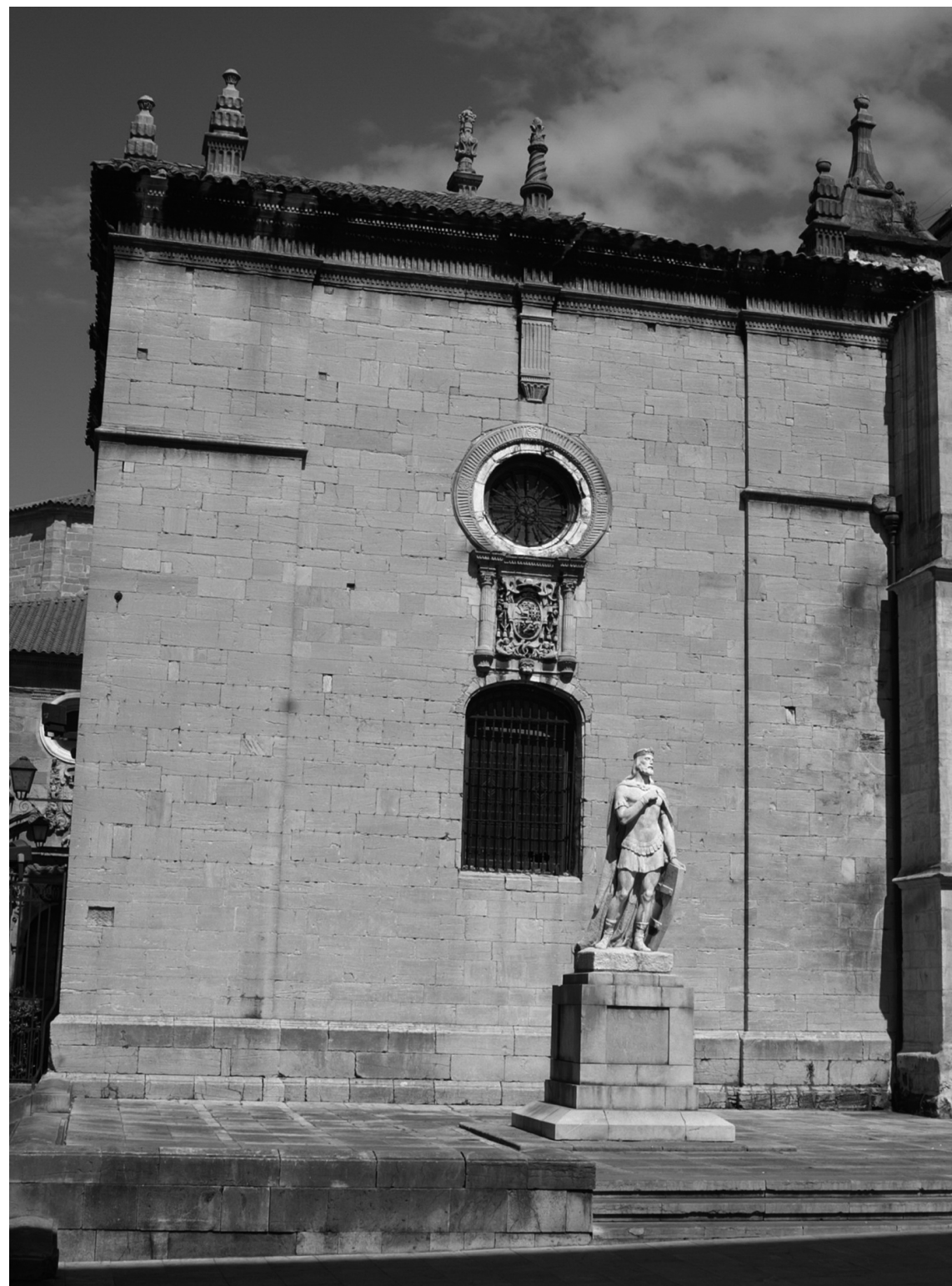

Fachada de la capilla de Santa Eulalia de la catedral de Oviedo, proyectada por Francisco Menéndez Camina (padre) en 1690.

\section{Capilla de Santa Eulalia}

Rematada la obra principal de la Catedral de Oviedo a finales del siglo XVI, las dos centurias siguientes se corresponden con la envoltura de la estructura gótica 
por sucesivos añadidos de varios estilos. El primero de ellos es la girola, encargada en 1621 a Juan de Naveda, a la que siguen varias capillas adosadas al cuerpo de naves promovidas por sucesivos obispos, para terminar con la construcción del la fachada de la Corrada del Obispo, la sacristía y el claustro alto, ya en el siglo XVIII.

Las reliquias de Santa Eulalia habían sido traídas a Oviedo, según la tradición, por el rey Silo (774-783) y a ella estuvo dedicado el piso inferior de la Cámara Santa hasta la llegada de los restos de Santa Leocadia. Con el auge al culto de las reliquias promovido durante la Contrarreforma, en 1621 se encarga una capilla para la santa a Juan de Naveda, que finalmente se ubica en la primera capilla (lado sur) de la girola trazada por Naveda, aunque en 1673 cambiará de advocación para dedicarla a la virgen de Covadonga. Antes de eso, en 1639, Santa Eulalia es proclamada patrona de la diócesis tras recibir la «petición de 9.000 votos de villas, lugares y personas principales» ${ }^{36}$.

Por último, en 1690 es el obispo Simón García Pedrejón (1682-1696) confesor de la reina Margarita de Austria quien asume la construcción de una capilla destinada a la santa que además sirviese como panteón familiar del comitente ${ }^{37}$. El proyecto fue contratado con Francisco Menéndez Camina y su hijo mayor el 23 de agosto de ese año 1690. Por cierto que hubo una cierta polémica entre arquitectos acerca de esta capilla, pues una vez contratada con los avilesinos, pujó en su construcción Gregorio de la Roza. Finalmente, el obispado confirmó el primer contrato con Menéndez Camina.

Se conservan dos trazas previas que dan cuenta de la evolución del diseño arquitectónico; la primera muestra un edificio de planta centralizada, con un espacio cuadrado del que se proyectan cuatro brazos apenas desarrollados. La cubierta se realizaría mediante bóvedas estrelladas, reflejando la profunda impronta que marcó el gótico en Asturias en el tema de las cubriciones, aportando soluciones que, en templos rurales, se siguieron aplicando hasta el siglo XVIII ${ }^{38}$. El segundo proyecto, más interesante, se aproxima a lo construido y presenta una zona central cubierta con cúpula del que se proyectan cuatro espacios. Las que se corresponden con la entrada y la cabecera presentan remate recto y cubierta de semicúpula. Las laterales, en cambio, son una especie de exedras cerradas con bóvedas en

36 RAMALLO ASENSIO, Germán: "Arquitectura barroca religiosa (I): La catedral de Oviedo» en BARÓN THAIDIGSMANN, Javier (dir.): El arte en Asturias a través de sus obras. Oviedo, Prensa Asturiana. 1996, p. 236.

37 Inicialmente, el cabildo había tratado de ampliar la capilla axial de la girola del templo para dedicarla a este culto. Sobre los orígenes del edificio y sus vicisitudes, v. MADRID ÁLVAREZ, Vidal de la: «El obispo Fray Simón García Pedrejón y la capilla de Santa Eulalia de Mérida en la catedral de Oviedo (16901696). Nuevas aportaciones». Liño no 14, Oviedo, 2008, pp. 39-47. Respecto a la función funeraria de la capilla, además del promotor, en tiempos más recientes la capilla ha sido lugar de enterramiento de otros prelados oventenses: Gregorio Ceruelo de la Fuente (1815-1838), Ramón Martínez Vigil (1884-1904) y J. B. Luis Pérez (1922-1934).

${ }_{38}$ En ocasiones, esa influencia toca también a construcciones cultas, como la capilla de Santa María del Rey Casto, muy próxima a la que nos ocupa y realizada a comienzos del siglo XVIII. En ella se utilizan pilares complejos y bóvedas estrelladas de clara inspiración medieval. 
forma de venera. Ambos proyectos cuentan con escasos vanos para la iluminación y pilares resaltados en las esquinas exteriores, aspectos éstos que se incorporarán al diseño definitivo.

En cierto sentido, este edificio representa una mezcla de la arquitectura de las capillas anteriores erigidas en el templo ovetense. Su estructura básica está formada por un cubo, que se corresponde en el interior con una planta centralizada con pilares apenas realzados en las esquinas que sirven de apoyo a la cúpula. El acceso se efectúa mediante vanos gemelos situados en los dos primeros tramos del cuerpo de naves. Toda esta disposición es simétrica con la capilla de Santa Bárbara (Nueva Cámara Santa) que ocupa el costado meridional ${ }^{39}$. De ella también toma la presencia de un entablamento corrido y de puertas y ventanas fingidas para decorar los muros. En lo que respecta a la cubierta, se planeó un óculo abierto en el centro de la cúpula, a imagen de la capilla del obispo Vigil de Quiñones, que finalmente no se realizó, quedando una bóveda ciega ${ }^{40}$.

En lo referente a la decoración, encontramos un contraste brutal entre el exterior y el interior de la capilla. Sus fachadas, realizadas en sillería, se presentan prácticamente desnudas, actuando el muro como principal protagonista. Se destacan ligeramente el zócalo y los pilares de las esquinas. Los vanos se reducen unos pequeños óculos decorados con molduras. En el costado occidental, que se corresponde con la fachada de la catedral, encontramos el escudo del promotor. En 1736, la iluminación fue modificada al abrirse, en los lados E y S, sendas ventanas bajo los óculos rematadas en arco carpanel. Únicamente en la zona superior encontramos alguna decoración, en forma de un friso bajo el alero, formado éste por sucesivas molduras, y del que bajan unas pilastrillas en el centro de cada uno de los lados, por encima de los óculos. La cubierta, a cuatro aguas, se anima con unos pináculos de formas bulbosas (en las esquinas) y cónicas con relieves espirales (en el centro de los muros) que reinterpretan los remates góticos de la catedral.

39 Esta capilla fue promovida por el obispo Bernardo Caballero de Paredes (1642-1661) y encargada a Ignacio de Cajigal en 1660. Como la construcción que nos ocupa, también comparte las funciones de culto y panteón del promotor.

40 Edificio contiguo a la capilla de Santa Eulalia, la encargó Juan Vigil de Quiñones († 1627), asturiano que alcanzó los episcopados de Valladolid y Segovia. Sus trazas, de artista desconocido hasta hace pocos años, han sido atribuidas a Juan de Naveda. Cf. RAMALLO ASENSIO, Germán: «El barroco» en VV.AA.: La catedral de Oviedo, t. 1. Oviedo, Nobel. 1999, p. 156 y notas 32, 34 y 35. 


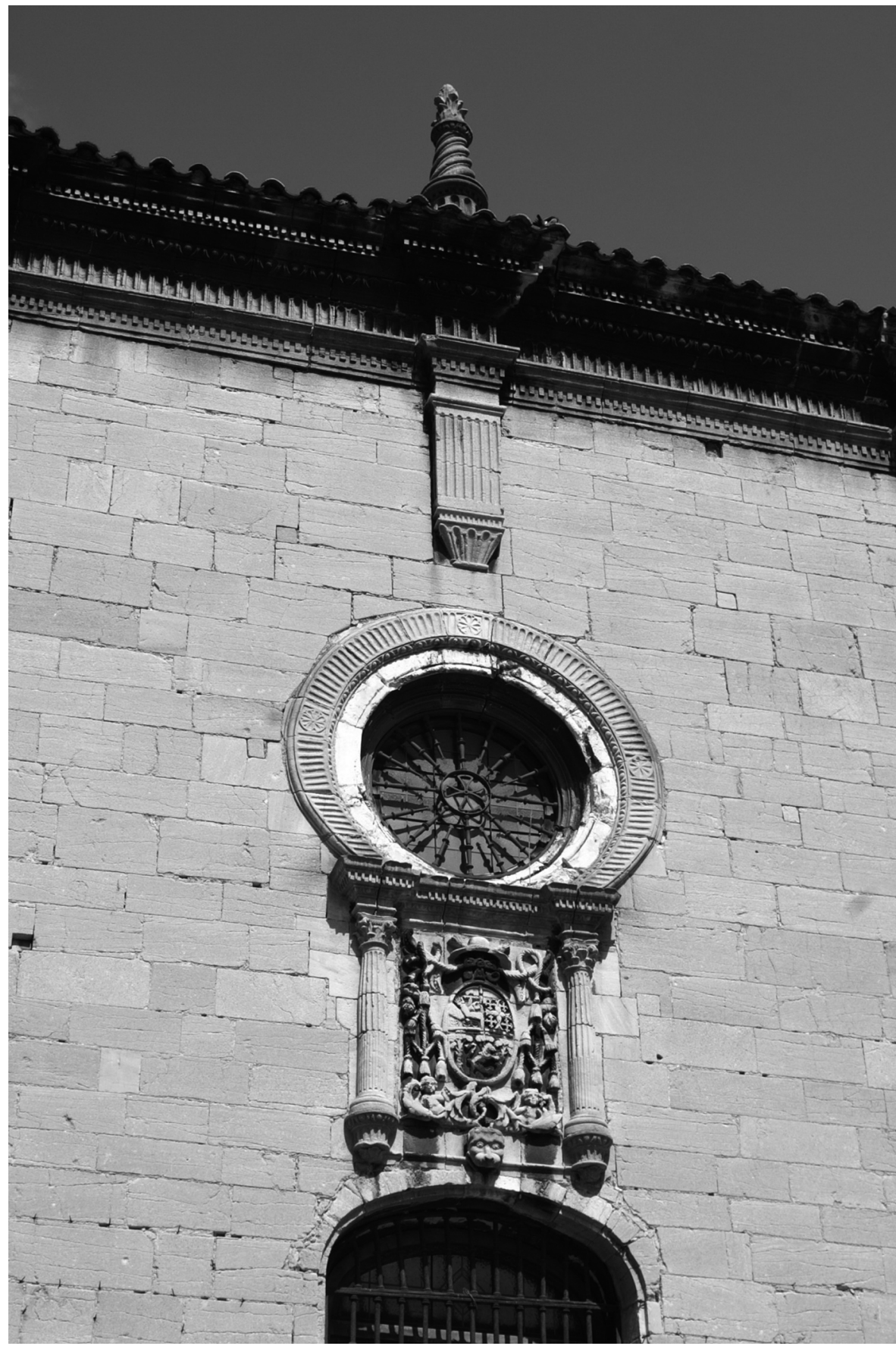

Detalle de la misma fachada, con el escudo del obispo García Pedrejón sobre el vano abierto con posterioridad. Obsérvese el rosetón, la disposición de la cornisa y el pináculo. 
En cambio, en el interior se hace gala de una exhuberancia decorativa hasta entonces desconocida en la arquitectura religiosa asturiana. El muro se articula gracias a una cornisa a la altura del arranque de los arcos que soportan la cúpula y que cuenta con un friso con decoración de guirnaldas. En cada lado, sucesivos órdenes de pilastras dividen el paramento, enmarcando los vanos y recurriendo a las guirnaldas, con florones en la parte inferior, que aparecen en los intradoses de los arcos de la cúpula. Las calles resultantes se rellenan con tarjetas y decoración de frutas, de gran efecto plástico.

Especial importancia adquiere el muro del imafronte. Sobre las puertas de entrada, resueltas mediante arcos de medio punto, se esculpe toda una escenografía que simula una tribuna alta con sus entradas y con decoración vegetal, soportada por un arco rebajado y a la que se accede por una puerta falsa emplazada entre los accesos. Las portadas de ingreso en la nave de la catedral se decoran a modo de arco triunfal, con columnas estriadas de orden corintio, entablamento con friso de florones y consolas y un frontón partido de volutas.

El las pechinas encontramos escenas del martirio de la patrona rodeadas de guirnaldas. Por su parte, la cúpula se divide en gajos separados con decoración frutal y cabezas de ángeles dando cierta impresión de venera. En el costado oriental de la capilla se adosa una pequeña sacristía rectangular, cubierta por dos bóvedas de crucería.

La capilla de Santa Eulalia plantea al espectador (que habitualmente no podrá penetrar en ella por encontrarse cerrada con verjas) una escenografía barroca animada por la luz, a pesar de no ejecutarse el proyecto original del óculo. El centro de la construcción lo ocupa un elemento indisociable de su arquitectura: el tabernáculo, contratado en 1697 con Domingo Suárez de la Puente, yerno de Luis Fernández de la Vega, quizá con trazas del propio Menéndez Camina ${ }^{41}$. Es una estructura soportada por columnas salomónicas y un ático muy desarrollado, disposición heredera de la ideada por Bernini para el Vaticano. En su interior se aloja la arqueta califal con los restos de la santa.

\section{Otras obras}

Una de las primeras obras documentadas de Francisco Menéndez Camina (padre), desgraciadamente desaparecida, fue la del convento de la Merced de Avilés. Los mercedarios residían desde la Edad Media en Raíces pero en 1670 realizaron una nueva fundación dentro de la villa de Avilés, siendo sus patronos los marqueses de Camposagrado. Dos años más tarde arrancan los trabajos de

41 RAMALLO ASENSIO, Germán: «El decorativismo en la arquitectura barroca asturiana. Los Menéndez Camina» en VV.AA.: Actas I Semana del Patrimonio Artístico Asturiano. Oviedo, Universidad de Oviedo. 1979, p. 91. Figura como arquitecto Juan García de Ascucha, un maestro mediocre, por lo que parece plausible una intervención de Camina. 
construcción con trazas del trasmerano Ignacio de Palacio, siendo maestro de obra Diego de Cantera. En 1685 se hace cargo de la obra Francisco Menéndez Camina. La orden fue poco a poco trasladando sus bienes al nuevo edificio, cuyo templo fue consagrado sin terminar en 1689. Finalmente, en 1703, la antigua propiedad de Raíces fue arrendada a un particular ${ }^{42}$. Sin embargo, el nuevo convento tendría una vida muy corta, pues fue desamortizado en 1836. Tras un fallido intento de trasladar allí la parroquia de Sabugo, en junio de 1855 la bóveda del templo se desplomó y en 1895 los restos fueron demolidos para erigir la nueva iglesia de Santo Tomás de Cantorbery.

Revisando los grabados y fotografías que han llegado a nuestros días, únicamente podemos analizar su fachada. Estaba formada por una zona central muy alargada, de dos pisos y sin decoración. En sus extremos se encontraban dos cuerpos resaltados, de los que el meridional debía de corresponden con las habitaciones del comendador, mientras que el septentrional era la fachada de la iglesia. Ambos estaban realizados en sillería y se coronaban con un entablamento corrido. El cuerpo sur presentaba un balcón de forja en el piso alto y el remate lo formaba una espadaña de un solo hueco terminada en frontón con bolas y flanqueada por volutas. La iglesia, por su parte, presentaba una espadaña de tres huecos, repitiendo el esquema de volutas y frontón, todo ello aplicado de una forma bastante clasicista. La decoración se limitaba al empleo de elementos arquitectónicos, como molduras lisas dividiendo los pisos y recercando los vanos con orejeras, así como los pilares resaltados en las esquinas.

42 GARRALDA GARCíA, Ángel: Avilés, su fe y sus obras. Avilés, Gráficas Summa. 1970, p. 281. 


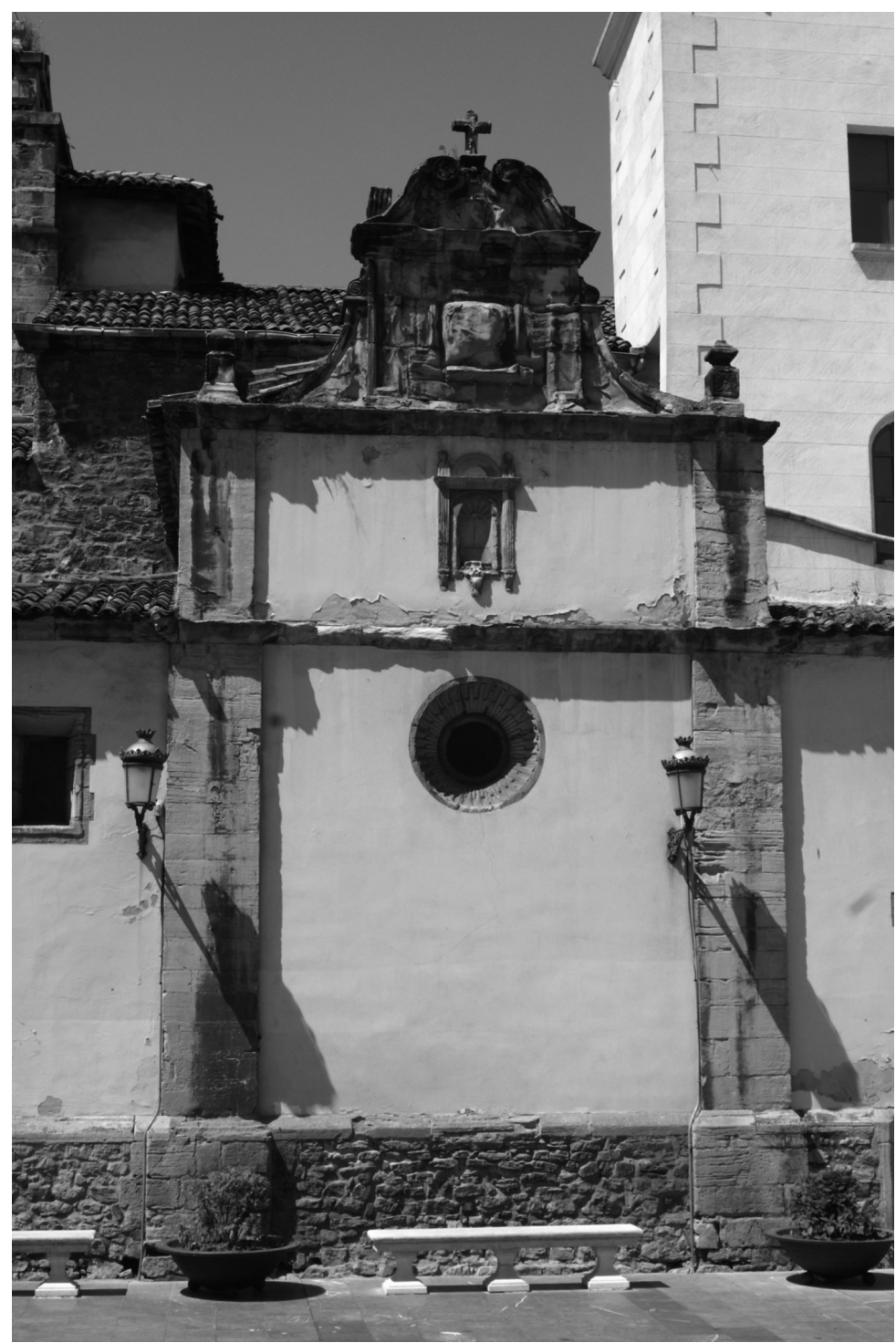

Fachada de la capilla del Cristo de San Nicolás de Avilés, atribuida a un miembro de la familia y realizada en la década de 1720. Su estructura se inspira en la fachada del convento de la Merced.

En cuanto al templo, únicamente su cuerpo fue obra de Menéndez Camina y constaba de una nave cubierta con bóveda de cañón con lunetos. Poseía capillas laterales y una pequeña sacristía en el costado meridional. La falta de fondos paralizó la obra, que fue rematada con trazas de Francisco de la Riva Ladrón de Guevara entre 1714 y 1723 con la realización de un crucero poco desarrollado y una cabecera poligonal. 
Como se dijo al más arriba, Francisco Menéndez Camina (padre) colaboró en la fachada de la iglesia de los jesuitas de Oviedo ${ }^{43}$, bajo la advocación de San Matías (en nuestros días parroquia de San Isidoro). El proyecto del templo es muy anterior, pues se atribuye a la fundación de Magdalena de Ulloa, quien lo encargó a Juan de Tolosa en 1583. Sin embargo, las obras no dieron comienzo hasta 1616 y la consagración tuvo lugar en 1681, con el edificio sin terminar.

Se le han adjudicado a Camina parte de la fachada y la decoración interior. Respecto a la primera, presenta algunos recursos en el cuerpo central que la emparentan con la obra del maestro avilesino, como el remate de volutas y hornacina del entablamento inferior y el uso de orejas muy desarrolladas en la ventana del cuerpo alto. También la profusa utilización de dentículos es atribuible a Menéndez Camina. Sin embargo, existen ciertos elementos discordantes, como la organización, de inspiración clasicista, de la portada o la compleja estructura del cuerpo superior, con columnas adosadas sobre consolas. En mi opinión, sí existió una intervención de Francisco Menéndez Camina pero podría ser modificando un proyecto preexistente ${ }^{44}$, del que quizá se aprovechó la organización del cuerpo bajo, al que se añadió el remate de la portada y el cuerpo alto.

Por lo que atañe al interior, no podemos descartar la participación de Camina y una cosa es segura: el avilesino conocía perfectamente la obra de este templo, pues aplicó su estructura, con sólo algunos cambios en la cabecera y el crucero, para la colegiata de San Juan Bautista de Gijón.

Francisco Menéndez Camina (hijo) es el autor de una obra residencial de cierta importancia en el centro de Avilés. Se trata de la casa de los García Pumarino (en la actualidad alberga el cine Marta y María) realizada en 1700-1706. Su solar estaba ocupado por cuatro casas y una huerta, y el edificio fue encargado por Rodrigo García Pumarino, oriundo de Manzaneda (Gozón) que había hecho fortuna en Perú y alcanzado la dignidad de caballero de Santiago.

Su fachada es interesante por conjugar una decoración propia de la arquitectura culta con una morfología popular, incorporando los soportales, elemento indispensable en las casas del casco urbano de Avilés a partir del siglo XVI. Realizada en sillería, presenta dos pisos divididos en cinco tramos por pilastras cajeadas rematadas en capiteles jónicos. Cada tramo consta de un arco de medio punto con molduras en el soportal de la planta baja, separado del piso alto por un friso de dentículos. Por encima, ventanas con balcones no volados recercadas por guirnaldas y dentículos. Bajo el alero encontramos un friso de veneras, una alusión

43 MADRID ÁLVAREZ, Vidal de la, y RAMALLO ASENSIO, Germán: «Arquitectura barroca religiosa (II)» en BARÓN THAIDIGSMANN, Javier (dir.): El arte en Asturias a través de sus obras. Oviedo, Prensa Asturiana. 1996, p. 254.

${ }^{44}$ La disposición de San Isidoro es muy semejante, por ejemplo, a la portada de la iglesia de los jesuitas de Bilbao, actual parroquia de los Santos Juanes, iniciada en 1624. En el templo vasco, sin embargo, es patente la herencia escurialense. 
a la condición de caballero de Santiago de su promotor. La calle central se resalta con decoración vegetal en las enjutas del arco.

Se sabe poco de la disposición interior de este edificio, perdida al acondicionarse como sala de cine, aunque parece que tenía un salón que daba a la calle. Se tiene constancia de que poseía un pequeño patio, capilla y huerta trasera.

La inspiración para componer esta fachada proviene de las alas laterales del Ayuntamiento, a su vez inspiradas en el proyecto de Juan de Naveda para Oviedo. Se trata entonces de un esquema clasicista al que, de una manera disimulada, se le ha incorporado una decoración barroca pero subordinada a los elementos arquitectónicos.

Una construcción religiosa de cierto empaque atribuida a Menéndez Camina hijo es el monasterio de San Salvador de Cornellana ${ }^{45}$. Este cenobio benedictino tiene una larga historia, que se remonta a la alta Edad Media y pasa por su adscripción al monasterio francés de Cluny en 1122. De su primera época se conservan un campanario y buena parte de la iglesia, fechadas en la primera y segunda mitad del siglo XII respectivamente. Durante el siglo XVII muchos monasterios asturianos renuevan sus fábricas y a Cornellana le llega su turno en 1696, cuando se contrata la edificación con los maestros avilesinos Domingo Suárez Solar y Francisco González Bango, si bien sus trazas provendrían de Francisco Menéndez Camina.

En esta fase se reedifican buena parte de las dependencias del monasterio, incluyendo el claustro y la fachada, así como los pies de la iglesia. En cuanto a las primeras, se articulan como un núcleo cuadrado en torno al claustro que, como es habitual en estos complejos, se encuentra al sur del templo. La fachada, bastante austera para los parámetros de los Camina, presenta dos pisos. El bajo se abre con pequeñas ventanas, que se corresponden con amplios balcones de vanos decorados con orejas en el piso alto. El cuerpo central adquiere un mayor protagonismo, mediante dos órdenes de columnas, jónicas con fuste estriado enmarcando la portada y salomónicas en el balcón superior. Por encima, un entablamento da paso a una disposición habitual en las fachadas de Camina, con escudo flanqueado por volutas bajo un remate mixtilíneo que apoya en dos pilastrillas que continúan los órdenes inferiores, como ocurre en el palacio de Camposagrado.

El claustro también presenta dos pisos y se encuentra perfectamente distribuido en cinco tramos por crujía mediante pilastras adosadas hasta la cornisa. Se decoran con casetones, alternando unos vacíos con otros decorados con rosetones, una disposición ensayada en la casa de los García Pumarino. Cada tramo se abre con un arco de medio punto en el claustro bajo y balcón con molduras en el

45 MADRID ÁLVAREZ, Vidal de la, y RAMALLO ASENSIO, Germán: «Arquitectura barroca religiosa (II)» en BARÓN THAIDIGSMANN, Javier (dir.): El arte en Asturias a través de sus obras. Oviedo, Prensa Asturiana. 1996, pp. 252-254. 
alto. La cornisa se resuelve con un friso de glifos y la cubierta se realiza mediante bóvedas con lunetos decoradas con yesería.

Por su parte, en la iglesia el tramo de los pies fue totalmente reedificado y provisto de tribuna alta. La fachada consta de dos torres de planta cuadrada y proporciones un tanto achaparradas que flanquean un cuerpo central más estrecho. La decoración es escasa y se reduce a la portada (vano arquitrabado flanqueado por columnas toscanas sosteniendo un entablamento). Por encima, una hornacina y óculos en cada una de las calles. Horizontalmente el muro está organizado por sucesivas molduras corridas, mientras que las torres y el cuerpo central presentan en los extremos pilastras levemente resaltadas. Las torres culminan en dos cuerpos de campanas de los que el superior de la torre norte está ocupado por un reloj.

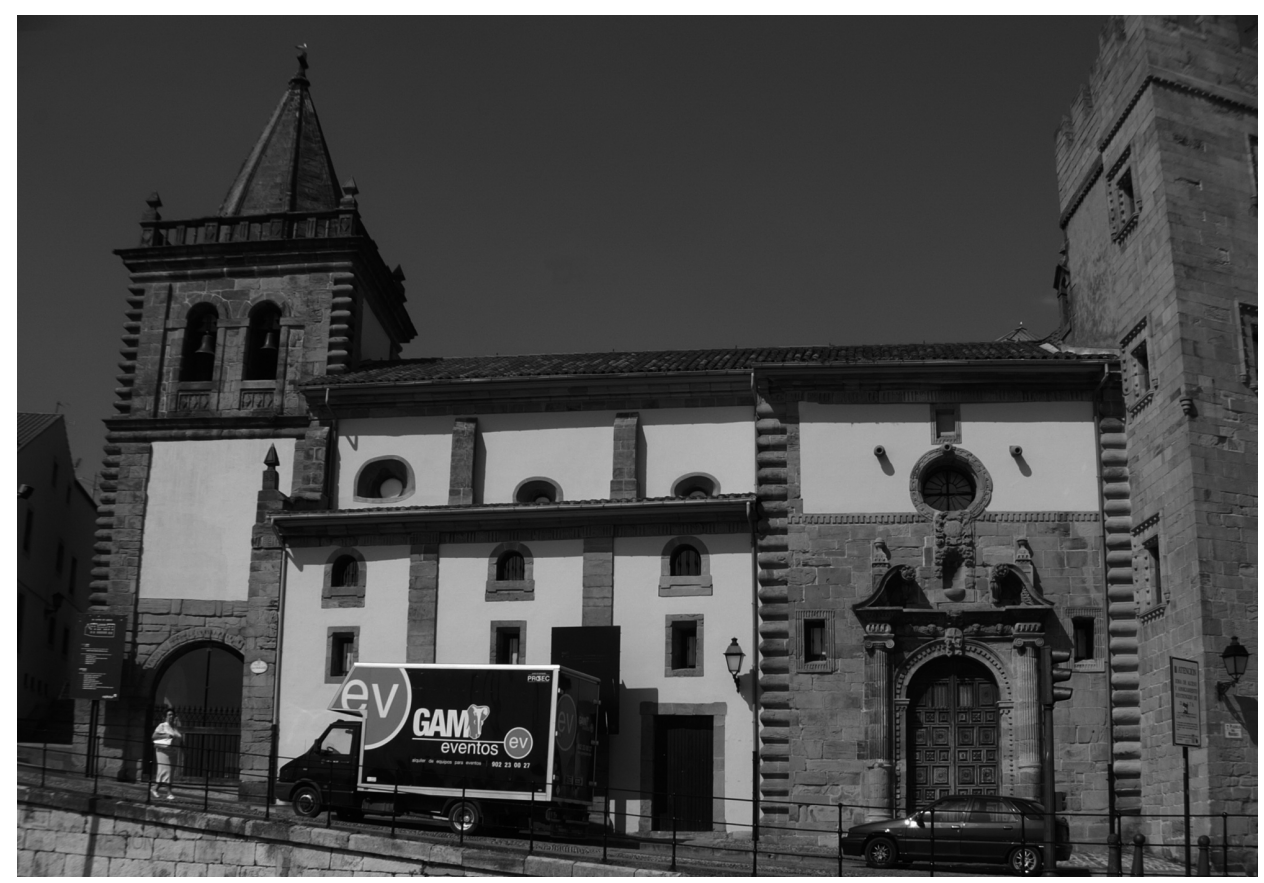

Vista de la colegiata de San Juan Bautista de Gijón. Reproduce el esquema jesuítico de San Isidoro de Oviedo en el cuerpo de naves, con torre a los pies coronada con una aguja de tradición medieval. También se aprecia la monumentalidad que adquiere la fachada del crucero, contigua a la del palacio, con una portada triunfal.

También en la villa avilesina encontramos un edificio que, si bien hasta ahora no ha sido atribuido a los Menéndez Camina, sí presenta similitudes que le hacen una posible obra suya, o al menos de su círculo de influencia. Se trata de la capiIla del Cristo en la parroquia de San Nicolás (hoy San Francisco). Se adosa al lado de la epístola y fue realizada en la década de 1720. Presenta planta cuadrada cubierta con cúpula sobre pechinas, que se ilumina con óculo y una pequeña linterna 
octogonal, disposición ya vista en la capilla de Santa Bárbara de la catedral de Oviedo. El interior es bastante sobrio, con decoración de florones en pilastras e intradoses de los arcos. El anillo de la cúpula aparece ornado con friso de ovas.

Al exterior presenta una fachada sencilla, con pilastras levemente resaltadas y un óculo. Sobre él, una imposta y una hornacina. El remate se realiza mediante una peineta coronada con un pequeño frontón de volutas que oculta hábilmente la linterna. La organización del muro parece inspirada en la capilla de Santa Eulalia, mientras que la disposición del remate recuerda la obra del desaparecido convento de la Merced. Todos estos elementos inducen a pensar en la colaboración o autoría de alguno de los miembros de la saga, quizá los más jóvenes, como Valentín o Bernardo, que aplicaron aquí, adaptándola a medios y espacio más reducidos, las enseñanzas adquiridas de sus mayores.

\section{INFLUENCIA DE LOS MENÉNDEZ CAMINA}

La trascendencia de la obra de la familia Menéndez Camina fue escasa. Como se comentó al principio de este artículo, la arquitectura asturiana del barroco depende sobre todo de los diferentes maestros que la ejecutaron más que de corrientes estilísticas perfectamente codificadas. Sin embargo, podemos citar aquí algunas obras de gran decorativismo que pudieron inspirarse en el legado de esta saga.

La primera es la capilla de Santa María del Rey Casto en la catedral, proyectada en 1705 por el trasmerano Bernabé de Hazas. Es una edificación peculiar, pues sustituye a la basílica edificada por Alfonso II el Casto a comienzos del siglo IX dentro del complejo episcopal y que fue utilizada como panteón de los reyes asturianos. Se adosa al brazo meridional del transepto y adopta una planta de nave única con capillas laterales, crucero cubierto con cúpula octogonal y cabecera ovalada. Sus puntos de conexión con los Camina son dos: la profusión decorativa (el edificio está muy próximo a la capilla de Santa Eulalia) y la persistencia de soluciones medievales. En este sentido, la capilla presenta pilares complejos que bajo órdenes clásicos ocultan una forma gótica como lo son las bóvedas de crucería que cubren la nave y que tienen cierto parentesco con el primer proyecto de Menéndez Camina para santa Eulalia.

Otra obra de esta corriente es el palacio del duque del Parque, también en la capital asturiana, encargado en 1723 a otro trasmerano, Francisco de la Riva Ladrón de Guevara. Este maestro debía de encontrarse en Oviedo desde hacía unos años, pues había realizado en 1718 la escalera del desaparecido convento de San Francisco ${ }^{46}$. El palacio presenta una fachada de dos pisos, perfectamente re-

46 SALTILLO, Marqués del: «Un arquitecto montañés desconocido. D. Francisco de la Riva (16861741)», Altamira oㅜ 1. Santander, 1934, p. 196. La sede de los franciscanos en Oviedo fue demolida en 1902 para levantar el palacio de la Diputación. 
ticulada mediante pilastras cajeadas, con sillares almohadillados en las esquinas y profusa utilización de los balcones como elemento monumental. La decoración se completa con la hipertrofia de las orejas de los vanos. A diferencia de la obra de los Camina en Gijón y Avilés (pero coincidiendo con otros palacios ovetenses como el de Malleza) prima el piso noble sobre el bajo, que queda reducido a una pequeña entreplanta abierta con ventanas y a un semisótano.

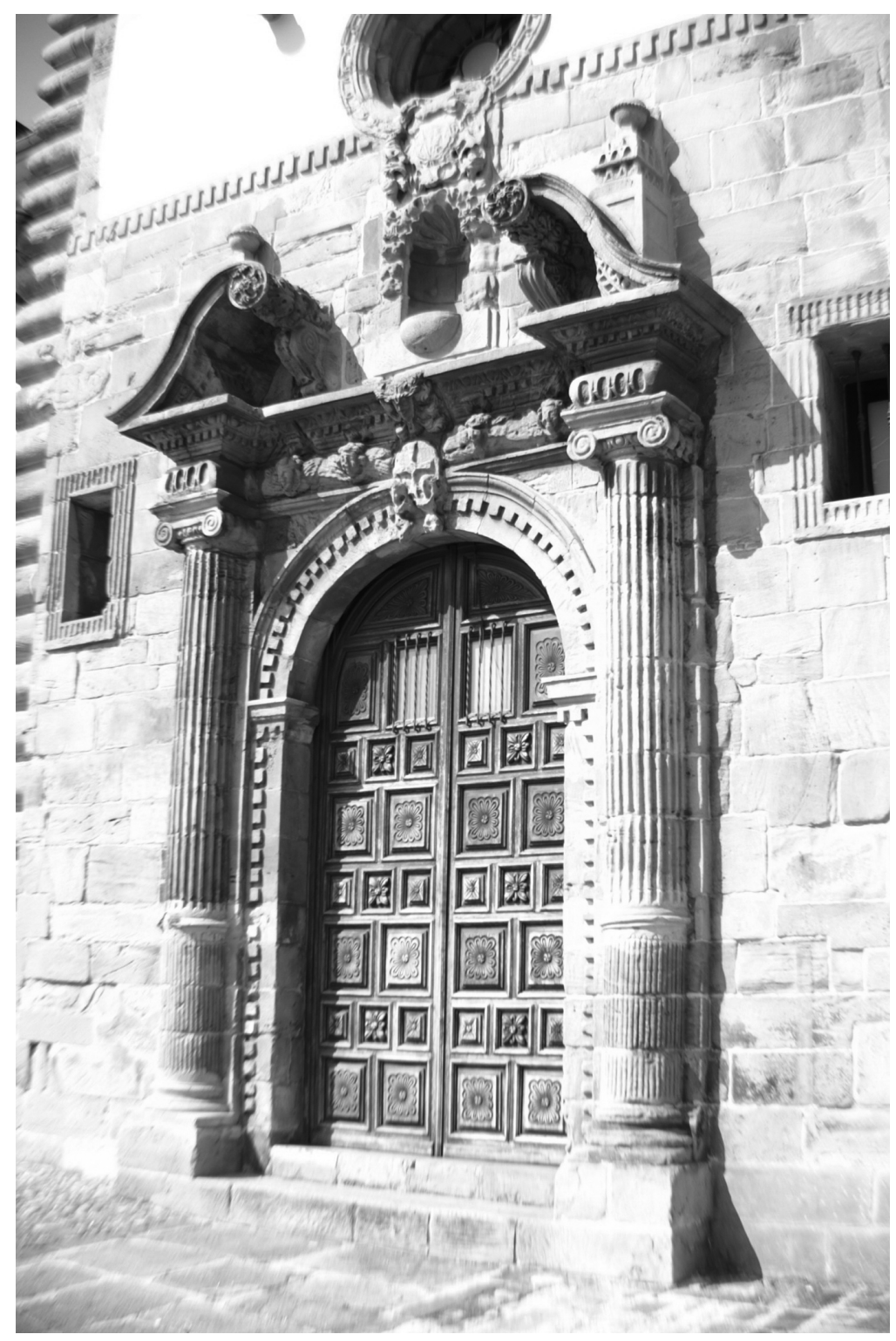

Detalle de la portada lateral de la colegiata de San Juan Bautista. 
Para cerrar este apartado, es preciso hacer una breve mención a la obra de Pedro Antonio Menéndez (1716-c. 1789) que, aunque no fue un discípulo directo de los Camina, sí representa la continuación de grandes maestros nacidos en el Principado que culminará con su discípulo, Manuel Reguera (1731-1798). Menéndez representa el ocaso del barroco decorativo y su transición hacia formas más clasicistas. Nacido en Candás, se le supone discípulo de Francisco de la Riva y sus principales obras se sitúan en Oviedo (palacio de Camposagrado y Hospicio) aunque también proyectó la reconstrucción del puerto de Gijón tras el temporal de 1749 e intervino en diversos templos parroquiales de la región.

Su estilo es en principio heredero del de Francisco de la Riva, con molduras muy trabajadas en torno a los vanos, aunque otros elementos como las pilastras cajeadas y los almohadillados del palacio de Camposagrado de Oviedo demuestran su conocimiento de la obra de los Camina. Lo mismo podemos decir del remate de la fachada del Hospicio, con una gran peineta que aloja el escudo, obra del escultor José Bernardo de la Meana. Sin embargo, sus proyectos comienzan a ser más sobrios, prescindiendo en ocasiones de una articulación del muro tan rígida y abandonando el recargamiento decorativo. Además, incorpora algunos elementos clasicistas como mascarones o un uso más canónico de los órdenes.

\section{CONCLUSIÓN}

La obra de los Menéndez Camina, especialmente la capilla de Santa Eulalia, ha sufrido duras críticas hasta hace bien poco por su exhuberancia decorativa y su aparente frivolidad. Estas opiniones pasan por alto los numerosos valores que la arquitectura de esta familia contiene. En primer lugar, su condición de maestros asturianos que, a pesar de no haber salido casi nunca de Asturias alcanzaron un grado de calidad en sus proyectos verdaderamente notable. Esa condición de nativos es más importante si tenemos en cuenta que fueron ellos los impulsores de una necesaria renovación en la arquitectura asturiana, que de otro modo hubiese quedado anclada en parámetros formulados a finales del siglo XVI.

Aunque su tarea apenas tuvo continuidad, las obras de los Camina constituyen el conjunto más sólido de edificios dentro del barroco asturiano, fiel reflejo del panorama artístico del momento. Francisco Menéndez Camina fue capaz, a partir de una formación probablemente muy limitada, de crear un lenguaje propio e innovador (dentro del contexto local) que fue apreciado por sus coetáneos y debió de proporcionarles un amplio reconocimiento si tenemos en cuenta que trabajaron para promotores tan importantes como los Bernaldo de Quirós o la catedral de Oviedo. 